\title{
Review Article \\ Breath Tests in Respiratory and Critical Care Medicine: From Research to Practice in Current Perspectives
}

\author{
Attapon Cheepsattayakorn ${ }^{1}$ and Ruangrong Cheepsattayakorn ${ }^{2}$ \\ ${ }^{1}$ 10th Zonal Tuberculosis and Chest Disease Center, Chiang Mai, 10th Office of Disease Prevention and Control, \\ Department of Disease Control, Ministry of Public Health, Chiang Mai 50100, Thailand \\ ${ }^{2}$ Department of Pathology, Faculty of Medicine, Chiang Mai University, Chiang Mai 50200, Thailand
}

Correspondence should be addressed to Attapon Cheepsattayakorn; attaponche@yahoo.com

Received 19 April 2013; Revised 12 August 2013; Accepted 14 August 2013

Academic Editor: Alejandro Comellas

Copyright (C) 2013 A. Cheepsattayakorn and R. Cheepsattayakorn. This is an open access article distributed under the Creative Commons Attribution License, which permits unrestricted use, distribution, and reproduction in any medium, provided the original work is properly cited.

Today, exhaled nitric oxide has been studied the most, and most researches have now focusd on asthma. More than a thousand different volatile organic compounds have been observed in low concentrations in normal human breath. Alkanes and methylalkanes, the majority of breath volatile organic compounds, have been increasingly used by physicians as a novel method to diagnose many diseases without discomforts of invasive procedures. None of the individual exhaled volatile organic compound alone is specific for disease. Exhaled breath analysis techniques may be available to diagnose and monitor the diseases in home setting when their sensitivity and specificity are improved in the future.

\section{Introduction}

Acetaldehyde breath test has been used to measure the production of this compound after ingestion of ethanol, but its interpretation is affected by many factors: ALDH2 polymorphism, alcoholic drinking habits, and smoking which are correlated with higher breath and blood levels [1]. The psychological expectancies of alcoholic drinking are more positive and less negative for ALDH $2^{*} 1 /^{*} 2$ genotype individuals with alcoholism, although the ALDH $2^{*} 2$ allele has been correlated with negative physiological responses in normal subjects [2]. Some authors have concluded that low levels of exhaled acetaldehyde cannot be used to measure blood levels [1]. Various pulmonary diseases involve oxidative stress and chronic inflammation [3]. These are not yet measured directly in routine clinical practice because of the difficulties in monitoring inflammation [3]. It is unsuitable for repeated use of fiberoptic bronchial biopsies as the "gold standard" and histamine or methacholine challenge for monitoring inflammation in patients with severe asthma and in children [3]. The interpretation of histamine or methacholine challenge in asthma measurement of airway inflammation may be confounded by the use of bronchodilator therapy [3]. This has led to the use of induced sputum to detect inflammation [4]. However, this technique is invasive and cannot repeat measurements in less than 24 hours [4]. The need to monitor pulmonary inflammation has led to the exploration of exhaled markers and condensates [5]. Breath test is presently a research procedure, but it may have an important place in the diagnosis and management of pulmonary diseases in the future [5].

More than a thousand different volatile organic compounds (VOCs) have been observed in low concentrations in normal human breath [6]. Despite this unflattering association with inebriation and arrest, breath testing is blossoming into an exciting area of medical technology [7]. Breath tests have attracted a great amount of clinical and scientific interests during the last decade [8]. Physicians have begun using these tests to diagnose an increasing wide variety of diseases without the hazards or discomforts of invasive procedures [7]. Furthermore, breath tests are providing important new insights into the understanding of basic biochemical functions of the body [7]. However, its sensitivity, variability, and reproducibility need to be addressed before it can be 
recommended as an outcome monitoring. Many of the new assays are now in development for predicting disease progression and response to present and novel therapies including indicating the disease instability.

\section{Exhaled Markers in Pulmonary Tuberculosis}

A study for breath biomarkers of tuberculosis (TB) was conducted among 23 and 19 patients with positive and negative sputum cultures for Mycobacterium tuberculosis ( $M t b c$ ), respectively, [9]. One hundred and thirty different VOCs which are mainly bloodborne generated were consistently detected in $M t b c$ cultures in vitro, predominantly derivatives of benzene, naphthalene, and alkanes [9]. Naphthalene,1methyl- and cyclohexane, 1,4-dimethyl- were observed both in vitro and breath [9]. Major VOCs which significantly increased in all hospitalized patients compared to the healthy controls were 1,3-isobenzofurandione, pentane, 2,3dimethyl-, acetaldehyde, benzenemethanol,_alpha _,_alpha_dimethyl-,cyclohexane, 1,1'-biphenyl, 2,2'-diethyl-, and 1hindene, 2,3-dihydro-1,1,3-trimethyl-3-phenyl- [9]. Pattern recognition analysis and fuzzy logic analysis of breath VOCs independently distinguished healthy controls from hospitalized patients with $100 \%$ sensitivity and $100 \%$ specificity [9]. Pattern recognition analysis identified patients with positive sputum cultures with $82.6 \%$ sensitivity and $100 \%$ specificity [9]. Accordingly, the $M$ tbc urease enzyme encoded by ureA (Rv1848), ureB (Rv1849), and ureC (Rv1850) hydrolyzes urea into carbon dioxide and ammonia [10]. An attractive point of urease-based diagnostics is that humans lack urease enzymes [11]. Since 2009, a group of investigators started studying the benefits of rabbit urease breath test for TB diagnosis (UBTTB) and treatment monitoring [11]. The specificity of UBTTB may be increased by introducing intravenous or inhaled ${ }^{13} \mathrm{C}$-urea tracer, thus preventing gastric Helicobacter species contaminations [11]. Anti-TB chemotherapy in the first two months and oral nonabsorbable urease inhibitors such as bismuth subsalicylate or proton pump inhibitors have also increased the specificity of UBT-TB for TB treatment monitoring by suppression of gastrointestinal Helicobacter pylori [12]. Thus, UBT-TB can be applied for diagnosis and treatment monitoring of human pulmonary TB $[12,13]$. A recent study on point-of-care (POC) breath test demonstrated that POC-breath test can detect VOCs which are the metabolic products, particularly derivatives of benzene, alkanes, and naphthalene of $M t b c$ in patients with active pulmonary TB with $80 \%$ accuracy, $71.2 \%$ sensitivity, and $72 \%$ specificity [14]. In age-matched subgroup, the accuracy increased to $84 \%$, and in a population with $5 \%$ prevalence, the POCbreath test detected active pulmonary TB with $13 \%$ positive predictive value and $98 \%$ negative predictive value [14]. Two previous studies revealed that gas chromatography-mass spectrometry (GC-MS) breath test can diagnose TB with $77 \%$ and $85 \%$ accuracies, $62 \%$ and $84 \%$ sensitivities and $84 \%$, and $64.7 \%$ specificities, respectively $[15,16]$, whereas a recent study showed very low concentrations of specific volatiles detectable by the same diagnostic tool for $M t b c$, Aspergillus fumigatus, and Pseudomonas aeruginosa [17].
Other several species of Halic produce VOC metabolites that act as chemical "fingerprints": M. avium, M. gordonae, M. gastri, M. kansasii, M. szulgai, and M. flavescens can be identified by their distinctive patterns of volatile metabolites, including C14-C26 fatty acids and their methylated and hydroxylated derivatives [18-20]. A study of clinical isolates of Halic with gas-liquid chromatography alone demonstrated that all strains of $M$. gordonae and $M$. kansasii were identified to species level [18]. $M t b c$ was definitely identified in $85 \%$ of the cases [18]. When it could not be definitely identified, the only alternatives were $M$. bovis and $M$. xenopi, both of which are rare causes of infection [18]. A recent study demonstrated that pulsed discharge helium ionization detector can detect o-phenyl anisole, methyl phenylacetate, methyl p-anisate and methyl nicotinate which are potential volatile biomarkers for species of Halic [21].

A study of exhaled hydrogen peroxide $\left(\mathrm{H}_{2} \mathrm{O}_{2}\right)$ level in patients with pulmonary TB revealed significantly decreased after 2 months of successful antituberculous treatment and its level did not correlate with circulating interleukin (IL)-18 in TB patients before or after treatment compared with control groups [22]. Nitric oxide (NO) is mainly generated in the bronchial system [5]. Patients with active TB demonstrated elevation of exhaled NO with NOS2 expression in alveolar macrophages and reduced with antituberculous treatment $[23,24]$. Nevertheless, some investigators reported that exhaled NO measurement had limited value in the direct diagnosis of pulmonary TB, although it revealed $84 \%$ sensitivity and $67 \%$ specificity, but it may be worth developing as a cost-effective replacement of chest radiography in screening algorithms of pulmonary $\mathrm{TB}$, where chest radiography is not available [25].

\section{Exhaled Markers in Pulmonary Cancer}

Alkanes and monomethylated alkanes are oxidative stress products that are excreted in the breath, the catabolism which may be accelerated by polymorphic cytochrome $\mathrm{p} 450$-mixed oxidase enzymes (CYP) that are induced in patients with pulmonary cancer and result in measurable changes in the composition of the breath [26]. In 2003, a study reported a breath test for C4 to C20 alkanes and monomethylated alkanes that provided a rational set of markers which identified pulmonary cancer in a group of patients with histologically proven disease [26]. Patients with pulmonary cancer demonstrated significantly high level of exhaled NO with the intensity of NOS2 expression in alveolar macrophage [27].

In 2007, a study concluded that a two-minute breath test can predict pulmonary cancer with accuracy comparable to screening chest computed tomography [28]. The accuracy of the test was not affected by TNM (tumor, node, and metastasis) stage of disease or tobacco smoking [28].

Alterations in breath VOCs in pulmonary cancer were consistent with a nonlinear pathophysiologic process, such as an off-on switch controlling high-risk CYP activity [28]. VOCs breath test with weighted digital analysis predicted pulmonary cancer with accuracy the same as chest computed tomography [29]. Its accuracy was not affected by tobacco 
smoking and TMN stage of disease [29]. In 2005, a study concluded that none of the exhaled VOCs alone was specific for pulmonary cancer; a combination of 13 VOCs does allow the classification of cases into groups [30]. A study using an electronic nose showed additionally different VOCs within different types of pulmonary cancer cells, especially 4 special VOCs that were demonstrated to exist in all culture media of cancer cells [31].

Exhaled VOC analysis may therefore be useful in improving the specificity and sensitivity of conventional diagnostic approach to pulmonary cancer [30]. A study showed that 67 VOCs were common to the breath samples of 62 (57.4\%) of pulmonary cancer patients [32]. The mean posttest probability of pulmonary cancer for combination of 22 breath VOCs, predominantly alkanes, alkane derivatives, and benzene derivatives in breath samples of patients with an abnormal chest roentgenogram was significantly higher in patients with pulmonary cancer than in those without pulmonary cancer (all stages $P<0.0003$ ) [32]. In patients with stage I pulmonary cancer, a posttest probability of 0.46 had $100 \%$ sensitivity and $81.3 \%$ specificity; a posttest probability over 0.90 had $66.7 \%$ sensitivity and $100 \%$ specificity [32]. Exhaled breath analysis can discriminate benign from malignant pulmonary nodules; furthermore, it can discriminate squamous-cell carcinoma and adenocarcinoma and early versus advanced disease stages [33]. A recent study demonstrated that exhaled breath tests with solid phase microextraction (SPME)-gas chromatography (GC)-Mass Spectroscopy (MS) can detect VOCs biomarkers for pulmonary cancer with $96.47 \%$ sensitivity and $97.47 \%$ specificity [34]. The diagnosis was correctly predicted by combination of age, tobacco smoking, and sex in $65.7 \%$ of cases, compared with $81.5 \%$ by the breath VOCs [32]. Cross-validation correctly predicted the diagnosis in $71.1 \%$ of patients with pulmonary cancer and $66.7 \%$ of those without pulmonary cancer [32]. In 2007, a study showed that sampling of exhaled NO can be used as a large screening test for pulmonary cancer [35] and another study demonstrated higher exhaled breath condensate (EBC) levels of IL-2, tumor necrosis factor (TNF)-alpha, and leptin in patients from stages 1 to 3 of nonsmall cell pulmonary cancer [36]. Exhaled matrix metalloproteinase-9 (MMP-9) in patients with progressive nonsmall cell pulmonary cancer measured in EBC was indicated to be significantly higher as well as in pleural effusion and whole blood and demonstrated positive correlation between MMP-9 levels in EBC, cigarette smoking status, and stage of pulmonary cancer [37]. A recent study of microsatellite alterations (MAs) of $3 \mathrm{p}$ in the EBC deoxyribonucleic acid (DNA) of patients with nonsmall cell pulmonary cancer revealed that MAs in EBC DNA of cancer patients were significantly more common than in normal subjects and MA profile of EBC DNA corresponded to that from cancer tissue of each patient [38]. Isoprene and acetone were shown to increase in the exhaled breath measured by SPME-GC-MS breath test after cytostatic chemotherapy indicating the usefulness of this technique in monitoring of pulmonary cancer-chemotherapy efficacy [39]. Some recent studies revealed reduction of mutated KRAS oncogene in EBC [40] and some VOCs in exhaled breath [41] after surgical resection of pulmonary tumor, particularly nonsmall cell type. Unfortunately, a recent study demonstrated that serial $\mathrm{FE}_{\mathrm{NO}}$ measurements during radiotherapy in patients with pulmonary cancer had a low ability to detect symptomatic radiation pneumonitis [42].

\section{Exhaled Markers in Respiratory Infections}

In 2005, a study reported that notably hydrogen cyanide (HCN) gas concentration was significantly higher above Pseudomonas aeruginosa (P. aeruginosa)-positive specimens than above other bacterial growths $(P<0.01)$, and levels of HCN greater than 100 part per billion were a sensitive (68\%) and highly specific (100\%) VOC of P. aeruginosa [43]. Increased exhaled $\mathrm{CO}$ levels with significantly decreasing after treatment were shown in patients with bacterial lower respiratory tract infection [44]. Elevated exhaled CO levels were also found in children [45] and adults [46] with upper respiratory tract viral infections. Decreased exhaled and nasal NO levels were seen in human immunodeficiency virus infected patients and more decreased in progressive cases [47]. Low exhaled and nasal NO levels were demonstrated in primary ciliary dyskinesia (PCD) or cystic fibrosis (CF) patients with recurrent bacterial or viral pulmonary infections or recurrent pulmonary parasitic infestations and patients with active Wegener's granulomatosis infected with Staphylococcus aureus [48]. The increasing of exhaled NO levels was observed in patients with chronic bronchitis [49] and bacterial upper [50] and lower [49] respiratory tract inflammations. In adults, NO is produced by the paranasal sinuses and its exhaled concentrations elevate in normal subjects after digested, intravenous, or inhaled L-arginine [51]. In normal subjects, nasal air contains only NO, whereas orally exhaled air contains both $\mathrm{NO}$ and $\mathrm{CO}$ [52]. A study demonstrated that 2-pentylfuran may be an exhaled biomarker for detection of pulmonary fungal and Streptococcus pneumoniae infections [53]. Higher concentrations of volatile fatty acids in the bronchoalveolar lavage (BAL) were observed in the patients with pneumonia infected with fermenting anaerobic bacteria which are neither found by microscopy nor cultivation [54].

\section{Exhaled Markers in Some Pulmonary Diseases}

Exhaled NO levels are increased in atopic asthma, normal in chronic obstructive pulmonary diseases (COPD) and asbestosis [55, 56], and reduced in CF and in PCD [57]. Elevated levels of EBC 8-isoprostane in both asbestosis and silicosis of leukotriene (LT) B4 in asbestosis and of LT D4 in silicosis were also observed $[56,58]$. Smoking is a factor which decreases exhaled NO levels [59] but a study showed statistically significant small and transient elevation in fractional exhaled $\mathrm{NO}\left(\mathrm{FE}_{\mathrm{NO}}\right)$ levels [60]. A recent study demonstrated that there was no statistically significant difference in $\mathrm{FE}_{\mathrm{NO}}$ concentrations between asthmatic and nonasthmatic patients with nasal polyposis [61]. $\mathrm{FE}_{\mathrm{NO}}$ was reduced by effects of both soluble and suspension formulations of nebulized budesonide in asthmatic children [62]. Patients with stable COPD are the same as the healthy smoking subjects [59]. Exhaled carbon monoxide (CO) is increased in asthma, 
CF, and COPD [57]. A study demonstrated no significant elevation of exhaled $\mathrm{CO}$ levels in patients with either allergic rhinitis or CF, or steroid-treated or steroid-naïve asthma, as compared with controls [63]. In inhaled-corticosteroid(ICS-) treated asthma patients, normal exhaled CO level was reported [64]. Raising and reduction of exhaled pentane were shown during acute asthma exacerbations and recovery, respectively, [65]. When compared with control subjects and steroid-treated patients, higher exhaled ethane levels were demonstrated in mild steroid-naive asthma patients [66]. In 2007, a study revealed that an electronic nose, a chemical sensor array, can discriminate exhaled breath of patients with asthma from healthy controls but is less accurate in distinguishing asthma severities [67].

Reduced EBC ammonium ions were observed in patients with acute asthma [68]. Exhaled prostaglandin $\mathrm{E}_{2}$ and $\mathrm{EBC}$ prostaglandin $\mathrm{F}_{2}$-alpha are markedly increased in COPD but not in asthma $[69,70]$. In contrast, LT E4 is increased in asthma but is not detectable in COPD patients and in normal subjects [71] as well as EBC thromboxane (Tx) $B_{2}$ (Montuschi et al., unpublished observation). EBC concentrations of prostaglandin D_methoxime are the same in normal subjects and COPD patients [69], whereas no $\mathrm{Tx} \mathrm{B}_{2^{-}}$ $\mathrm{Ll}$ is detectable in COPD patients [68] but is measurable in about $50 \%$ of asthmatic patients [70]. Some studies showed detectable levels of the LT B4, C4, D4, E4, and F4 in EBC of normal and asthmatic subjects $[72,73]$, especially EBC C4, D4, and $\mathrm{E} 4$ in patients with moderate and severe asthma [73] with close correlation with disease severity [74], but no correlation with pulmonary function tests [74]. In patients with moderate asthma with steroid withdrawal lead to elevation of EBC B4, C4, D4, and E4 levels and worsening of asthma [75]. Elevation of B4 levels was demonstrated in EBC of patients with moderate or severe asthma [73], COPD exacerbations [76], and stable COPD [69] and was shown in the sputum of patients with bacterial exacerbations of COPD [74] and bronchiectasis [77] as well. EBC LT B4 may be involved in asthma exacerbations and may contribute towards neutrophils recruitment (Montuschi et al., unpublished observations). Unchanged EBC N (epsilon) (carboxymethyl)lysine levels in nonsmoking asthmatics and significant elevation in smoking asthmatics were observed [78]. Higher EBC $\mathrm{Th} 2$-specific macrophage-derived chemokine and eotaxin, an eosinophil chemoattractant, levels were demonstrated in ICStreated asthmatics compared with the steroid-naïve asthmatics or controls [79]. Nonselective cyclooxygenase inhibitors elevate $\mathrm{B} 4$ and decrease prostaglandin $\mathrm{E}_{2}$ levels in $\mathrm{EBC}$ in COPD patients, whereas selective cyclooxygenase inhibitors have no effect [80].

In nonsmoking COPD patients, there is elevation of exhaled $\mathrm{CO}$ levels and also during exacerbations but decreases during recovery, respectively, [44, 81]. Elevation of exhaled ethane levels in smoking COPD patients [82] and elevation of exhaled isoprene [83] levels which are correlated with cholesterol biosynthesis [8] and pentane [84] levels in normal smokers [85] were shown. Increased levels of exhaled pentane and ethane which are found in inflammatory diseases [8] and elevation of exhaled and nasal NO, but not pentane, were also demonstrated in the patients with obstructive sleep apnoea with active inflammation [86] including lower EBC $\mathrm{pH}$ [87]. Elevation of exhaled 8-isoprostane levels, a marker of oxidative stress [88] by doubled and about 3fold in patients with mild and severe asthma, respectively, which correlated with the disease severity, irrespective of corticosteroid treatment, excepted reduction of malondialdehyde (MDA) levels with treatment [89]. Elevation of both $\mathrm{EBC}$ and plasma MDA levels is found in asthmatic patients [90]. A study revealed that EBC MDA was related to both changes in pulmonary function and air pollution exposure [91]. Reduced EBC chlorine and serum eosinophilic cationic protein concentrations in asthma patients with airborne pollen exposure were found in a study [92]. Significant rapid decreases in S-nitrosothiols levels and nitrite/nitrate ratios but no changes in EBC 8-isoprostane levels were observed in patients with mild asthma who were treated with budesonide [93]. Elevation of exhaled sulphur-containing compounds levels was observed in allograft rejection and hepatic failure [8]. Elevation of EBC 8-isoprostane levels was also observed in normal cigarette smokers and COPD patients with much greater extent [94], further elevated during exacerbations [76] and is associated with disease severity [93-97], and 8-isoprostane [98] and nitrite [99] levels may reflect the pulmonary emphysema extension. In smoking persons, measurement of biomolecules in sputum supernatants and EBC, cellular analysis of induced sputum, measurement of $\mathrm{FE}_{\mathrm{NO}}$, and measurement of breath VOCs with electronic nose application which can differentiate healthy smoking individuals from healthy nonsmoking subjects $[67,100]$ are noninvasive biomarkers of pulmonary inflammation and oxidative stress in subjects with cigarette smoking [100]. EBC IL6 [46], MDA [101], S-nitrosothiols [102], and nitrite [102] are elevated in patients with COPD, and there is further elevation of IL-6 [103], IL-1-beta [101], TNF-alpha [81], and $\mathrm{H}_{2} \mathrm{O}_{2}$ [104] during exacerbations compared with normal smokers. No significant differences for EBC erythropoietin (EPO) concentrations or correlation between EPO and TNFalpha levels were observed in COPD patients except that TNF-alpha concentrations were significantly higher in COPD patients than in non-COPD patients [105]. A study on EBC metallic elements in COPD patients revealed higher levels of aluminum, cadmium, and lead and lower levels of copper and iron with particular interest of EBC copper levels because of their positive correlation with pulmonary function parameters [106].

In stable and exacerbation CF patients, there are markedly elevation of exhaled $\mathrm{CO}$ levels and decrease after treatment. This indicates that exhaled CO level is a marker of CF severity [107]. In 2000, a study reported increased concentrations of EBC 8-isoprostane in stable CF patients compared with control subjects [108]. CF patients demonstrate increasing of exhaled ethane levels, which is significantly correlated with airway obstruction and increased exhaled CO levels [109]. CF patients with exacerbations or stable period showed elevated levels of nitrite, nitrate [110,111], and nitrotyrosine (NT) [112] in EBC and sputum [113]. Elevation of EBC nitrite and S-nitrosothiols is shown in adult patients with more severe CF [114] compared to CF children [115]. A study 
revealed failing of EBC free 3-NT as a marker for oxidative stress in stable CF and asthma children [116]. A study on 12 exhaled VOCs in young CF patients showed a significantly higher levels of pentane and 2-propanol, lower levels of dimethyl sulphide, correlation with median forced expiratory volume in one second $\left(\mathrm{FEV}_{1}\right)$ for toluene in these patients, and no discrimination of CF patients from healthy subjects for ethane levels [117]. These VOCs were not correlated with CF genotype, treatment with ICS and deoxyribonuclease, or atopic status [117]. EBC TNF-alpha, interferon-gamma, IL-2, IL-4, IL-5, and IL-10 levels can be detected in CF or asthma children [118] with reduction of EBC IL-8 levels and increasing of $\mathrm{pH}$ values after antibiotic treatment [119]. EBC $\mathrm{pH}$ values show a significant mean difference between asthmatics and nonasthmatics [120] and its variability is not influenced by clinical status changes [121]. Elevated concentrations of EBC sodium and chloride ions were shown in CF patients and correlated with disease severity and the sweat test (Balint et al., unpublished observation). The percentages of methane producers in CF patients are higher than in normal subjects, but there is no difference between methane producers and nonproducers with respect to the degree of malabsorption among CF patients [122]. Glucosehydrogen breath test after an overnight fast more likely shows elevation of fasting exhaled hydrogen levels compared with controls suggesting a high prevalence of small bowel bacterial overgrowth in these patients [123]. Use of inhaled ipratropium and laxatives is associated with a decreased risk of positive glucose-hydrogen breath test, whereas the use of azithromycin shows an increased risk [123].

Increased concentrations of $\mathrm{NO}, \mathrm{CO}$, ammonia, pentane [51], ethane [51], nitrite, $\mathrm{H}_{2} \mathrm{O}_{2}, 3-\mathrm{NT}$, adenosine [124], and 8isoprostane are found in EBC in inflammatory pulmonary diseases including pneumonia, bronchiectasis, lung transplantation, idiopathic pulmonary fibrosis, and adult respiratory distress syndrome (ARDS) [44-127]. Elevation of exhaled ethane levels is correlated with disease severity and activity in interstitial lung disease patients [128]. A study on bronchiolitis obliterans syndrome (BOS) developed after lung transplantation revealed that helium slope had better sensitivity for detection of stages $0-p$ and 1 BOS than either exhaled NO or CO levels and the best sensitivity was observed with the three combined markers [129]. A recent study in lung transplant recipients indicated that the $\mathrm{EBC} \mathrm{pH}$ variability was relatively small and similar to that in healthy nontransplant subjects [130]. Small amounts of exhaled ethane may be formed in the airways of asthmatic patients, whereas the major fractions of exhaled ethane, pentane, and isoprene seem to be of systemic origin [131]. Elevated EBC 3-NT [132] levels were also observed in patients with asthma including elevated EBC $\mathrm{H}_{2} \mathrm{O}_{2}$ [133] levels in patients with severe and unstable asthma. Whether bronchiectatic patients are treated with ICS or not, exhaled CO levels are elevated in them [134]. Exhaled NO levels seem to be decreased among patients with bronchiectasis infected with $P$. aeruginosa [135]. Increasing of exhaled CO and reduction of exhaled NO levels compared with patients without pulmonary hypertension and control subjects were observed in patients with systemic sclerosis [134-138]. However, the NOS3 levels in pulmonary vessels are variable [139-142]. Increasing of exhaled CO and NO levels was demonstrated in patients with fibrosing alveolitis $[136,143]$ and associated with disease activity [144]. The elevation of exhaled NO concentration originates from the alveolar level in the patients with alveolitis and from the bronchial level in the patients with asthma [60]. Either normal [145] or increasing [146] exhaled NO levels including elevation of EBC nitrite and nitrate concentrations [145] were reported in patients with active pulmonary sarcoidosis and reduced [146] by steroid treatment. A study in patients with newlydiagnosed pulmonary sarcoidosis showed that EBC TNF-alpha, plasminogen activator inhibitor 1, insulinlike growth factor 1 , and BAL specimens were comparable and closely positively correlated [147]. In contrast, EBC IL-6 level was significantly lower compared with BAL level [147]. A recent study in sarcoidosis patients revealed that there were positive correlations between EBC and BAL LT B4 levels and 8-isoprostane levels, higher EBC and BAL cysteinyl leukotriene (cysLT) and 8-isoprostane levels compared with normal subjects, positive correlations between EBC LT B4 levels and the number of BAL lymphocytes per milliliter and between the number and percentage of BAL eosinophils and EBC 8-isoprostane and BAL cysLT levels, and no correlation between EBC eicosanoid levels and BAL macrophages, BAL lymphocytes, or superoxide production percentages [148]. A previous study revealed that liquid chromatography (LC) in combination with mass spectroscopy can accurately and quantitatively assess eicosanoids in EBC, particularly LT B4 and 8-isoprostane in patients with asthma and other respiratory diseases [149]. Some previous studies demonstrated that the combination of gas chromatography or LC and nuclear magnetic resonance (NMR) spectroscopy metabolomics profiling of EBC can increase sensitivity and specificity of the EBC analysis of small molecular weight metabolites [150, 151]. NMR spectroscopy metabolomics applied to EBC can characterize airway biochemical fingerprints, particularly in asthma pathophysiology [152].

\section{Exhaled Markers in Critically Ill Patients}

A study among patients with head injury, ARDS, and those being at risk of developing ARDS concluded that plasma concentrations of MDA [153] and thiobarbituric acid-reactive substances [153] as well as breath concentrations of pentane $[51,153]$ and ethane increased with increasing inflammatory status. Exhaled hydrocarbon concentrations may be affected by contamination from bacterial flora in the gastrointestinal tract [51]. Acetone concentrations which are correlated with lipolysis [8] and dextrose metabolism [8] are not different between patient groups [85]. Significant correlation between exhaled breath acetone which is the most abundant human breath VOC [117] and propanol levels is seen in normal subjects [154] and elevation of exhaled acetone levels is observed in healthy subjects during exercise [155]. Isoprene concentrations are lowest in the ARDS group [153]. When compared with critically ill mechanically ventilated patients without pulmonary infection, there are reduced isoprene and increased pentane eliminations in these patients with pulmonary infection [156]. After cardiopulmonary bypass in 
adult patients, association of reduced exhaled NO levels with the decrease in pulmonary compliance and the increases in alveolar arterial pressure and pulmonary artery may indicate ARDS [157]. Significant elevation of $\mathrm{EBC} \mathrm{H}_{2} \mathrm{O}_{2}$, hydrogen ions, and LT B4 levels was demonstrated in patients after pulmonary lobectomy [158]. Summary of studied volatile organic compounds is shown in Table 1.

\section{Discussion}

Several of the commonly occurring VOCs are derived from metabolic pathways that have been previously reported [163], for example, isoprene from the mevalonic acid pathway of cholesterol synthesis [163] and alkanes which are markers of oxygen free radical (ORF) activity in vivo [164]. ORF's degrade biological membranes by lipid peroxidation, converting polyunsaturated fatty acids to alkanes which are excreted through the lungs as VOCs [164]. A breath test for C4 to C20 alkanes and monomethylated alkanes provides a rational set of markers that identified pulmonary cancer in a group of patients with histologically proven disease [26]. It is limited by the following three main factors: the limited range of presenting disorders among the patients, the comparatively small number of patients with pulmonary cancer, and the comparative large number of variables in the breathmethylated alkane contour [26], a three-dimensional marker of oxidative stress [165].

The screening method must have acceptable technical performance parameters and must detect the disease at an earlier stage than would be possible without screening, while minimized false-positive and false-negative results [26]. In addition, early detection must improve disease outcome, cost, feasibility, and acceptability of screening and early treatment should be established [26]. The breath test is comparatively acceptable to patients, technically feasible, and low in cost [26].

Bronchial biopsies provide mediators and inflammatory cells, as well as the spatial relationships between the inflammatory processes in the airway wall, but they may not reflect all pathologic changes in the lung periphery, and the bronchoscopic invasiveness precludes repeated measurements. BAL may provide more information on small airway and alveolar inflammation, but it has variable dilution and invasiveness. Induced-sputum examination can provide information about mediators, cells, and markers of oxidative/nitrative stress, but it has high variability of the biomarkers.

High reproducibility of $\mathrm{FE}_{\mathrm{NO}}$ measurements within a single day in both children and adults is superior to any conventional methods of airway inflammation in asthma that may allow physicians to perform two instead of three exhalations for obtaining the reliable results [166] and reduce the cost of medical care [93]. This leads to their strong association with airway inflammation [159], asymptomatic asthmatic patients [167], insensitivity to beta-2 agonists [159], their high sensitivity to steroid treatment [168] which may significantly reduce the cost of research and medical care [93], noninvasiveness [166], and minimally staff-training procedures [166]. $\mathrm{FE}_{\mathrm{NO}}$ does require an extra encouragement, compared with peak expiratory flow measurements [169]. Systemic errors or "learning effects" of serial $\mathrm{FE}_{\mathrm{NO}}$ measurements are not found [170]. The measurements will not be accepted unless they are performed by following the guidelines [171]. A study showed requirement of only a small number of asthmatic patients for demonstration of a $25-80 \%$ effect of a studied drug in clinical trial [170]. When the $\mathrm{FE}_{\mathrm{NO}}$ levels are below or above a certain reference level, steroid treatment should be either increased or reduced [172]. A study in lifelong never-smoking adults recently revealed that the geographic mean of $\mathrm{FE}_{\mathrm{NO}}$ for the whole population was 16.6 parts per billion (ppb) and the upper limits of $\mathrm{FE}_{\mathrm{NO}}$ ranged from 24.0 to $54.0 \mathrm{ppb}$ [173]. Height and age would account for 9 to $11 \%$ of the variance of reference values [174]. Such upper $\mathrm{FE}_{\mathrm{NO}}$ values are definitely higher than those reported in both normal adults and children in American Thoracic Society/European Respiratory Society (ATS/ERS) guidelines [175] and in a study by Olivieri et al. [176]. Recently, a study reported that $\mathrm{FE}_{\mathrm{NO}}$ was significantly higher in patients with chronic rhinosinusitis and allergic rhinitis compared to patients with nonallergic rhinitis [177]. Seasonal variations of $\mathrm{FE}_{\mathrm{NO}}$ values due to fluctuations of exposure to allergens have been reported [174]. According to this hypothesis, the measurements should have been reported whether performed outside or during pollen season [178]. With asthma and rhinitis having a same weight in $\mathrm{FE}_{\mathrm{NO}}$ changes as recently reported in a random community survey of adults [179]. Probably missing in statistical analysis [173] or in replies to the questionnaire [180] of the high prevalence of nasal symptoms and/or allergic rhinitis and dietary consumption of fats in asthmatic children assuming low levels of antioxidants [181]. These could be important confounders for $\mathrm{FE}_{\mathrm{NO}}$ reference values. NO chemiluminescence analyzers are mainly available in academic research laboratories and are presently expensive [166]. However, due to advances in technology, eventually it may be possible to introduce these devices in patients' homes [166]. Recently, $\mathrm{FE}_{\mathrm{NO}}$ measurement with a portable analyzer has been used beneficially for young adults with asthma screening [182] including handheld device for $\mathrm{FE}_{\mathrm{NO}}$ measurements in asthmatic children [178]. Therefore, repeated $\mathrm{FE}_{\mathrm{NO}}$ measurements will not interfere with the system and be able to be used much more frequently, in contrast to the currently used semi-invasive or invasive procedures [159]. It is likely that the methods for nasal NO measurement need to be substantially standardized because of the high nasal NO levels from constitutive sources in the nose [183]. Flushing the nose with helium may reduce contamination of exhaled breath with nasal air that contains high NO levels, which may potentially influence the results of NO-related markers (S-nitrosothiols, nitrite/nitrate) [110]. One of the serious limitations of the exhaled aliphatic hydrocarbon [184] measurement is its requirement of large sample volume [185]. Today, there are a small number of researches using the hydrocarbon breath test as a marker of human lipid peroxidation [159, 164], but a study showed nonspecific [32]. The main reasons for the limited use of this method are technical difficulties [166]. The scrupulous avoidance of air contamination, the use of the right materials, an appropriate washout period, adequate preinjection concentrations of the samples, and a sensitive 
TABLE 1: Summary of studied diseases, studied volatile organic compounds and references.

\begin{tabular}{|c|c|c|c|c|}
\hline \multirow[t]{2}{*}{ Studied diseases } & \multicolumn{3}{|c|}{$\begin{array}{l}\text { Studied exhaled breath }{ }^{*} \text { and in vitro volatile organic compounds and exhaled } \\
\text { breath condensates** }\end{array}$} & \multirow[t]{2}{*}{ References } \\
\hline & Breath & & Culture (in vitro) & \\
\hline \multirow[t]{2}{*}{ Pulmonary tuberculosis } & \multirow{2}{*}{\multicolumn{3}{|c|}{$\begin{array}{l}\text { (1) Benzene, ethyl-* } \\
\text { (2) Benzene, methyl-* } \\
\text { (3) Benzene, propyl-* } \\
\text { (4) Heptane, 3-methyl-* } \\
\text { (5) Propane, 2-methoxy-2-me* } \\
\text { (6) 1-Octene* } \\
\text { (7) Cyclohexane* } \\
\text { (8) Heptanal } \\
\text { (9) Heptane, 2,4-dimethyl-* } \\
\text { (10) Heptane, 4-methyl-* } \\
\text { (11) Nonanal* } \\
\text { (12) Pentane, 2-methyl-* } \\
\text { (13) Styrene* } \\
\text { (14) Tridecane* } \\
\text { (15) Cyclohexane, 1,3- } \\
\text {-dimethyl-, trans-* } \\
\text { (16) Benzene, 1,4-dichloro-* } \\
\text { (17) Cyclohexane, 1,4- } \\
\text {-dimethyl-* } \\
\text { (18) 1-Octanal, 2-butyl-* } \\
\text { (19) 2-Butanone* } \\
\text { (20) Naphthalene, 1-methyl-* } \\
\text { (21) Camphene* } \\
\text { (22) Decane, 4-methyl-* } \\
\text { (23) Heptane, 3-ethyl-2- } \\
\text { methyl-* } \\
\text { (24) Octane, 2,6-dimethyl-* } \\
\text { (25) Benzene, 1,2,3,4-- } \\
\text {-tetramethyl* } \\
\text { (26) Icycle_3_1_1 hept-2- } \\
\text {-ene, 3,6,6-trimethyl-** } \\
\text { (27) Cyclohexane, 1-ethyl-4-methyl-, } \\
\text { trans-* } \\
\text { (28) 1-_beta_-Pinene* } \\
\text { (2) }\end{array}$}} & {$[9,15-18,24]$} \\
\hline & & & & $\begin{array}{c}{[10-} \\
13,22,23,25]\end{array}$ \\
\hline Pulmonary cancer & & $\begin{array}{l}\text { (1) 1,5,9-Cyclododec } \\
\text { (2) Pentan-1,3-diold } \\
\text { (3) Benzoic acid, 4- } \\
\text { (4) Propanoic acid, } \\
\text {-methyl-1,3-propane } \\
\text { (5) 10,11-Dihydro-5H } \\
\text { (6) 2,5-Cyclohexadi } \\
\text { (7) Benzene, 1,1-oxy } \\
\text { (8) Furan, 2,5-dime } \\
\text { (9) 1,1-Biphenyl, 2,2 } \\
\text { (10) 3-Pentanone, 2, } \\
\text { (11) trans-Caryophy } \\
\text { (12) 1H-Indene, 2,3- } \\
\text { (13) 1-Propanol } \\
\text { (14) Decane, 4-metl } \\
\text { (15) 1,2-Benzenedic: } \\
\text { (16) 2,4-Hexadiene, }\end{array}$ & $\begin{array}{l}\text { 5,9-trimethyl-* } \\
\text { ate, 2,2,4-trimethyl-* } \\
\text { thyl ester* } \\
\text {, 1-(1,1-dimethylethyl)-2- } \\
\text { (B,F)-azepine* } \\
\text { ione, 2,6-bis(1,1-dimethylethyl)-* } \\
\text { yl-* } \\
\text { l,1,3-trimethyl-3-phenyl-* } \\
\text { acid, diethyl ester* } \\
\text { thyl- }{ }^{*}\end{array}$ & $\begin{array}{l}{[26-34,36-} \\
39]\end{array}$ \\
\hline
\end{tabular}


TABle 1: Continued.

\begin{tabular}{|c|c|c|c|}
\hline \multirow[t]{2}{*}{ Studied diseases } & \multicolumn{2}{|c|}{$\begin{array}{c}\text { Studied exhaled breath* and in vitro volatile organic compounds and exhaled } \\
\text { breath condensates }{ }^{* *}\end{array}$} & \multirow[t]{2}{*}{ References } \\
\hline & Breath & Culture (in vitro) & \\
\hline \multirow[t]{2}{*}{ Pulmonary cancer } & & 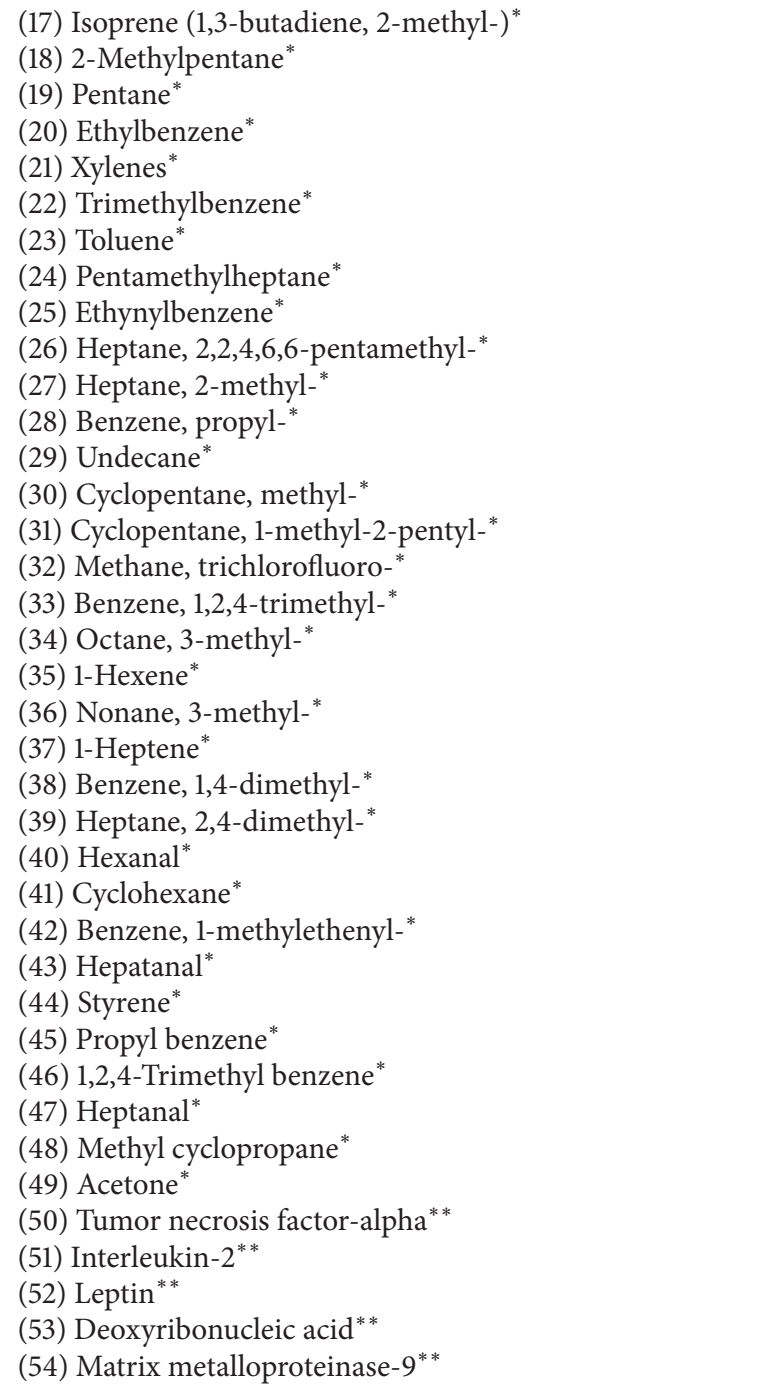 & $\begin{array}{l}{[26-34,36-} \\
39]\end{array}$ \\
\hline & & Nitric oxide* & {$[27,35]$} \\
\hline
\end{tabular}

Respiratory

infections/infestations

Pseudomonas aeruginosa

Staphylococcus aureus

Bacterial

Viral

Parasitic

Streptococcal pneumoniae Aspergillus niger Aspergillus terreus Aspergillus flavus Aspergillus fumigatus Fusarium species
(1) Hydrogen cyanide*

(2) Nitric oxide*

$[43,135]$

Nitric oxide ${ }^{*}$

(1) Nitric oxide*

(2) Carbon monoxide*

$[44,48$

(3) Volatile fatty acids (BAL)

$50,54]$

(1) Nitric oxide*

(2) Carbon monoxide*

[45-48]

Nitric oxide*

2-Pentylfuran* 
TABle 1: Continued.

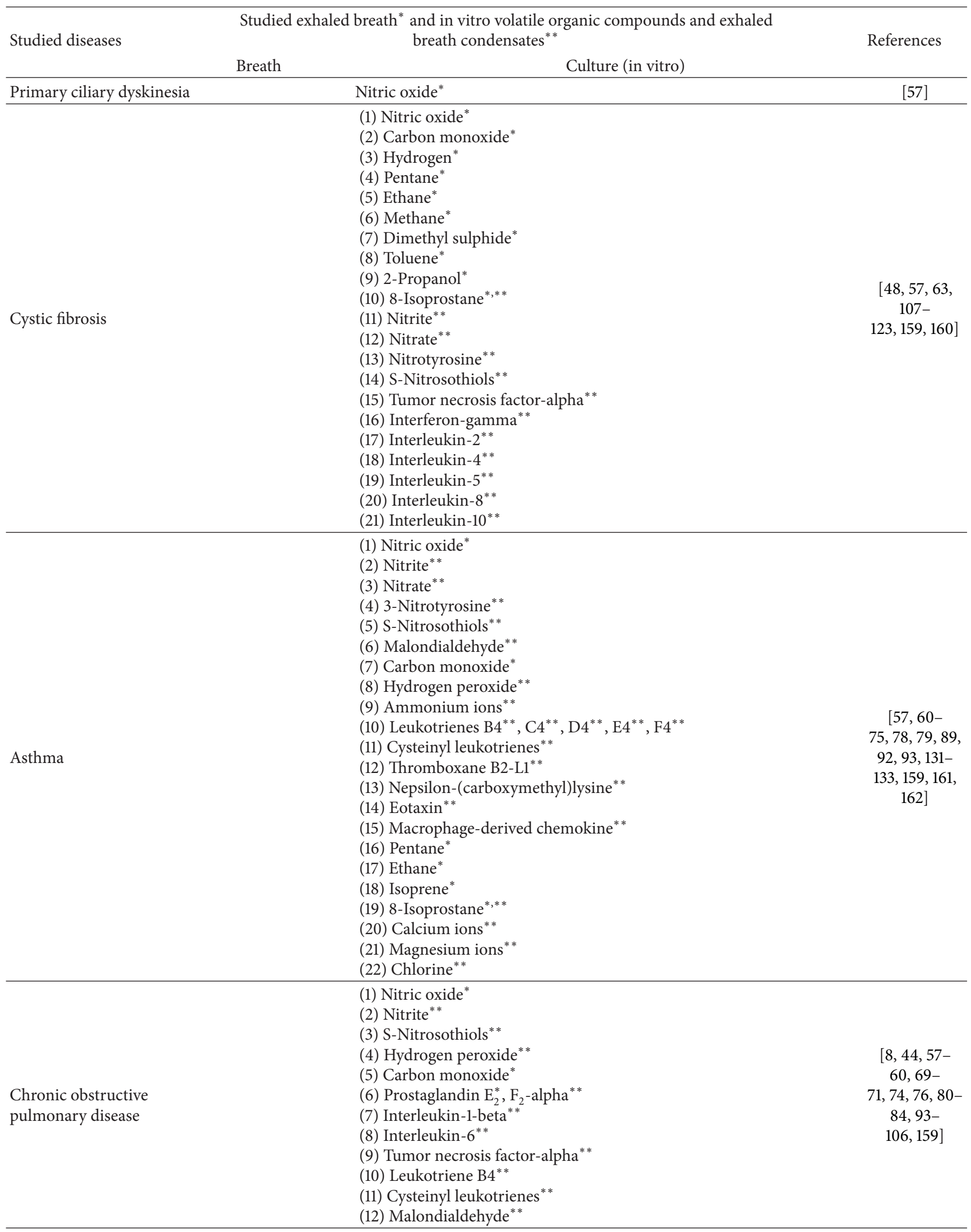


TABle 1: Continued.

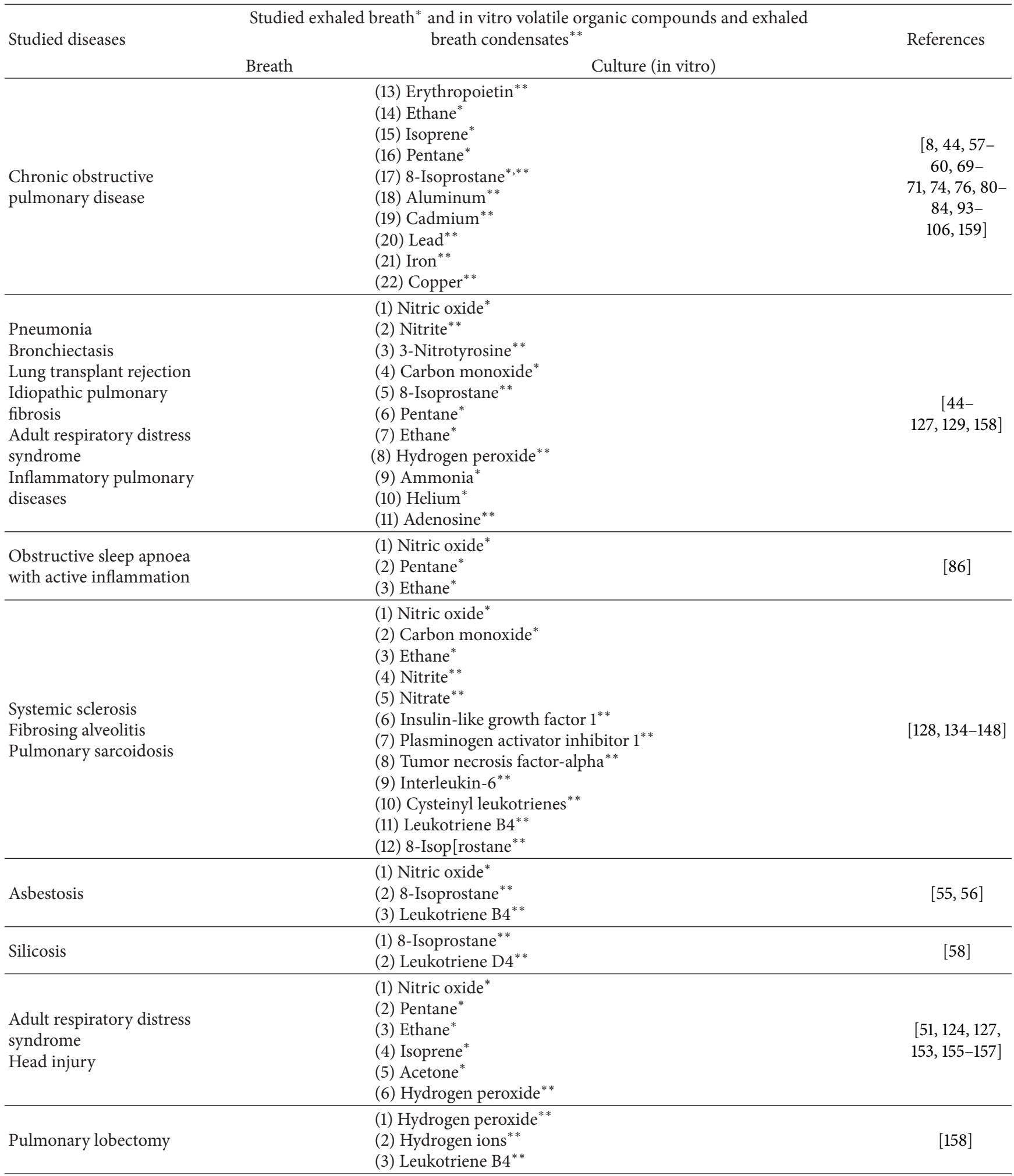

gas chromatographic technique enable the reproducible and accurate human breath hydrocarbon measurement [166].

There is strong evidence that EBC composition abnormalities may reflect biochemical changes of airway lining fluid and potentially be used to measure the targets of modern therapy in COPD and asthma clinical trials [6]. Recently, most of the centers use a commercially available condenser that allows to collect a small volume of EBC within a few 
minutes and is equipped with a spirometer to register the exhaled air volume $[75,186,187]$. However, there are reports that cysLTs were undetectable in the EBC collected with a commercially available condenser [188]. It is unclear if this was due to the technical characteristic of this condenser, but another commercially available condenser can easily detect EBC cysLT in patients with asthma, both adults [73] and children [57], and COPD [69]. A recent Japanese asthma study showed significant correlation between urine LT E4 and EBC cysLTs levels in low-dose ICS treated patients, significant correlation between $\mathrm{FE}_{\mathrm{NO}}$ and $\mathrm{EBC}$ cysLTs in steroid-naïve asthmatics, and no correlation between EBC cysLTs and $\mathrm{FEV}_{1}$, or log PC20Arc [161]. EBC LT B4 levels in patients with various pulmonary diseases [189] and NT levels in asthmatic [72] and CF [190] patients were validated by reversed-phase high-performance liquid chromatography. There is no significant difference between $\mathrm{EBC} \mathrm{H}_{2} \mathrm{O}_{2}$ from neonates from a background with nasal continuous positive airway pressure alone or ventilator [191]. The spectrophotometric method commonly used to measure $\mathrm{EBC} \mathrm{H}_{2} \mathrm{O}_{2}$ levels lacks specificity in ARDS due to the presence of variable levels of sample contaminants [192]. An elevation in calcium and a deficiency in magnesium concentrations in EBC have been reported in atopic asthma [162] as well as elevated EBC lactic acid levels in patients with acute bronchitis [193]. Identification and measurement of EBC proteins are controversial [194]. TNF-alpha, IL-1-beta, soluble IL-2 receptor protein, and IL-6 in EBC of patients with various respiratory conditions have been reported [162]. Higher concentrations of total EBC protein have been shown in young smokers compared with nonsmokers, whereas TNFalpha and IL-1-beta levels were not different [160]. EBC IL8 levels are more than doubled in unstable CF patients but are mildly increased in stable CF (Balint et al., unpublished observations). EBC collection can be successfully applied in healthy and asthmatic children with $100 \%$ success rate and negligible fall in $\mathrm{FEV}_{1}$ [195]. Although ratios of EBC compounds can provide insights into pulmonary redox status, issues of dilution remain critically important for the understanding of exact chemical constituents of the airways [196]. EBC can supplement $\mathrm{FE}_{\mathrm{NO}}$ to more fully elucidate the nitrogen oxide chemistry of the lungs and airways [196]. EBC assays may monitor inflammation, oxidative stress, and acid stress [196]. A study revealed that $\mathrm{EBC}$ hydrogen ions, $\mathrm{H}_{2} \mathrm{O}_{2}$, and LT B4 elevated significantly in patients after pulmonary lobectomy, but not after the milder insult associated with cardiac surgery [158]. This indicates that EBC is a safe, noninvasive method of sampling the milieu of the distal lung and is sufficiently sensitive to detect markers of oxidative stress and inflammation in adults [166]. ATS/ERS Task Force on EBC provides the following general recommendations for 1-2 milliliters of oral specimen collection: collect during tidal breathing using a saliva trap and nose clip; 10 minutes collection time and define cooling temperature; use condenser with inert material; do not use filter and resistor between the condenser and subject [197]. A study suggested that tidal and minute volumes can predict the expected amount of collected EBC both in normal and airway disease subjects [198]. EBC represents a larger respiratory tract portions than
BAL [197]. Comparison of EBC and BAL biomarkers in patients undergoing bronchoscopy for clinical indications in a study showed significantly higher $\mathrm{pH}$, nitrogen oxides, and 8-isoprostane in EBC than in BAL, no different levels of $\mathrm{H}_{2} \mathrm{O}_{2}$ in $\mathrm{EBC}$ and $\mathrm{BAL}$, significantly higher BAL protein levels, higher EBC phospholipid levels, and no different levels of keratin in EBC and BAL [199]. These indicate that the exact origin of EBC substances from different parts of the respiratory tract to each biomarker is still unknown [199]. Choice of dilutional marker is debatable [199]. There is yet no consensus on whether urea, electrolytes, or conductivity may be useful [199]. EBC has no introduced external factors compared with BAL [199]. Thus, EBC dilutional factors should be easier to assess [199]. Both techniques have significant potential limitations in addition to a significant reduction of exhaled NO levels with unknown underlying mechanisms led by bronchoscopy [200] and EBC sampling cannot be directly compared with BAL information [199]. Solubility, volatility, electric charges of EBC biomarkers, and collection technique may be involved [199]. The important areas of rapidly evolving $\mathrm{EBC}$ information for future studies involve ascertaining site and mechanisms of EBC particle formation, improving reproducibility, determination of dilution markers, EBC employment in longitudinal studies, determining the utility of EBC measures for the management of individual patients [197], and the cellular source of airway inflammation [201].

A study demonstrated a fundamental flaw in the breath pentane assays: the column employed in the gas chromatography did not separate pentane from isoprene, the most abundant compound in the breath [202]. What Mendis and colleagues reported in 1995 [203] as breath pentane was probably a mixture of pentane and isoprene [202]. A study noted that the details of Sobotka PA and colleagues' analytical technique that reported in 1994 [202] were sketchy; they may not have really been observing isoprene because most chromatographic columns do not separate pentane from isoprene [202, 204]. Increased clearance of alkanes and methylalkanes by CYP enzymes-induced smoking is consistent with previous reports that tobacco smoking is a potent inducer of CYP enzymes [205-207]. Increased circulating levels of conjugated dienes [208] and MDA [207, 209] in patients with pulmonary TB which indicated both local and systemic oxidative stress [210] were reported in addition to increased many breath VOCs among these patients [9] while existed only local reaction by slightly elevated levels of EBC hydrogen peroxide and thiobarbituric acid-reactive substances in sarcoidosis patients [210]. Currently, there is yet no single exhaled marker sufficiently sensitive and specific for diagnosis of sarcoidosis [211]. It may be assumed that serum total reactive oxygen metabolites levels can be used as an activity criterion in the differentiation of active and sequel pulmonary TB [212]. Sensitivity and specificity of pulmonary TB diagnosis can be increased with GC-MS breath tests [15, 16].

Currently, there is relative lack of information about how theses biomarkers are related to their reproducibility, disease severity, outcomes of concurrent therapies, and other clinical outcomes. None of the exhaled markers are diagnostic 
for a particular pulmonary disease, apart from very low exhaled and nasal NO in PCD. Single exhaled markers are usually evaluated in isolation, but markers are affected differently in different diseases, and their sensitivity varies to certain techniques. For example, as indicated above, COPD is characterized by normal or little elevation in exhaled NO, and by greater elevation in exhaled 8 -isoprostane and $\mathrm{CO}$ levels [159]. By contrast, CF patients typically show low exhaled NO and high exhaled 8-isoprostane and CO levels [159], whereas asthma is characterized by a large elevation in exhaled NO, a moderate elevation in exhaled 8-isoprostane and CO [159], and elevation in EBC LT E4 levels which is not detectable in COPD [71]. Exhaled NO levels appear to be more sensitive to inhibition by low-dose ICS in asthma than exhaled 8-isoprostane and CO levels [159]. Nevertheless, monitoring of these markers may help differential diagnosis of pulmonary diseases. The choice of which biomarker is measured will depend on the clinical problem that is being addressed or posted; research questions for example, prediction of steroid responsiveness may be provided by increased sputum eosinophils and $\mathrm{FE}_{\mathrm{NO}}$. The use of $\mathrm{FE}_{\mathrm{NO}}$ measurements may minimize the potential long-term side effects of ICS $[213,214] . \mathrm{FE}_{\mathrm{NO}}$ analyzers are approved by the United States Food and Drug Administration for assessing and monitoring therapy in asthmatic patients, particularly with eosinophilia and patients with airway inflammation [214]. $\mathrm{FE}_{\mathrm{NO}}$ measurement can reduce approximately $40 \%$ of daily dose of inhaled glucocorticoids with similar efficacy and reduce costs [214]. Nevertheless, $\mathrm{FE}_{\mathrm{NO}}$ is only one surrogate biomarker of airway inflammation, but unlikely to ruminate the whole complexity of the inflammatory process in respiratory diseases and its multiple expressions within a given syndrome or disease [214]. Omics technologies (genomics, transcriptomics, proteomics, lipidomics, breathomics, and metabolomics), a novel omics technology that is purposed at detecting and quantifying breath biomolecules by reference analytical techniques and detecting selective profiles of breath VOCs by electronic nose and that requires close interdisciplinary interactions (biophysics, bioinformatics, and bioengineering), could have important implications for the pharmacological therapy of respiratory diseases [214]. With identification of subphenotypes of patients with respiratory diseases, it would facilitate the implementation of a personalized and tailored pharmacotherapy [214]. The omics technologies could also have therapeutic implications in asymptomatically maintained lung-function patients with ongoing pulmonary inflammation who might require starting pharmacological treatment [214]. Conclusions of randomized clinical trials are whether omics technologies able to apply to large patient populations, but they are still the best tool for evaluation of the pharmacological profiles of novel and existing drugs [214]. Most researches have now focused on markers in asthma; some data refer to infections, $\mathrm{CF}$, and PCD surrogate markers [215]. The use of $\mathrm{FE}_{\mathrm{NO}}$ measurement in treatment decision costs less than asthma management based on standard guidelines and has similar health benefits [216]. Although an exhaled NO elevation is not specific for asthma, the exhaled NO measurement can be used in distinguishing asthma from other obstructive airway disease conditions [217]. Elevated exhaled NO may indicate reflects some, but not all, aspects of airway inflammation, and needs further studies to determine how it relates to some other airway inflammatory markers (e.g., IL-4, IL-5, IL-6, IL8, IL-10, and TNF-alpha) [159]. Cryptococcus neoformans is a pathogenic fungus that produces large amounts of urease which catalyzes the hydrolysis of urea to ammonia that can be detected in exhaled breath [218]. It is possible that exhaled ammonia measurements might differentiate bacterial and viral infections in a variety of pulmonary diseases [159].

In the past, $\mathrm{H}_{2} \mathrm{O}_{2}$ was the most studied substance on numerous inflammatory diseases as a marker of oxidative stress [219]. Today, exhaled NO has been studied the most and its relevance to clinical practice markers of inflammation into daily practice should be evaluated [209]. There is a pressing need for the evaluation of these techniques in long-term clinical studies [5]. In the future, each disease may have a fingerprint or profile of different markers that may be diagnostic. Possibilities for measurement of exhaled breath markers are far greater than presently realized. Application of proteomics with high resolution two-dimensional gel electrophoresis and microanalysis of protein spots may allow the recognition of particular protein patterns in various diseases including malignancies and the origin of EBC proteins [199] and may result in the recognition of new therapeutic targets, many other markers of inflammation, and even specific fingerprints of activation or diagnostic proteins [159].

Measurement of exhaled breath temperature and humidity is another method which may serve as a simple, nonspecific, and inexpensive method for home monitoring of rhinitis, COPD, CF, and asthma including assessment of anti-inflammatory treatment effects [159]. A study supported the hypotheses that exhaled breath temperature is associated with the degree of airway inflammation in asthma [220]. EBC temperature influences condensate $\mathrm{pH}$ but not total protein content [221]. Condenser type influences total protein content, cysLT concentration, and sample $\mathrm{pH}$ [221]. These indicate that EBC temperature and adherence of the biomarkers to condenser surface may play a role but does not fully explain the variability of EBC biomarker levels [221]. So EBC collection temperature should be controlled and reported [222]. EBC standardized guidelines should include the most valid condenser coating for specific biomarker measurement [223]. For example, a condenser with glass or silicone coating is more efficient for albumin or 8-isoprostane measurement [223]. Liquid chromatography-electrospray ionization tandem mass spectrometry (LC/MS/MS) which has been used to analyze exhaled LT B4 levels in asthmatic children serves as a fast and easy method to assess the utility of EBC biomarkers for differentiation of pulmonary diseases [224] and is potentially suitable for longitudinal studies and drugtherapy assessment in patients with pulmonary diseases, but a presently important limitation is its high cost [201]. Recently, LC/MS/MS method has been used successfully to detect EBC urea, adenosine, adenyl purines, and adenosine monophosphate (AMP) and elevated AMP/urea ratios in CF patients [225]. Laser magnetic resonance spectroscopy can be a simple alternative to mass spectrometry in detection of 
exhaled ${ }^{14} \mathrm{C}$-urea in Helicobacter pylori infection [226, 227]. A method of gas chromatography combined with ultraviolet spectroscopy has been used to measure exhaled acetone and isoprene levels in diabetic school children [228] and to monitor pulmonary cancer-cytostatic chemotherapy efficacy [39]. Polymer-coated surface-acoustic-wave resonators are portable instruments which have been introduced and are able to analyze organic vapors [229]. The selected ion flow tube technique for trace gas analysis of air and breath is sensitive and can be used during a normal breathing cycle [230].

\section{Conclusions}

Measurements of exhaled hydrocarbon and other exhaled markers are much more difficult using current technology. EBC value will depend on availability of reliable, fast, and inexpensive detector systems and standardized collection that will overcome its high cost and its present highly variable measurements. This could have far-reaching potential for the diagnosis and treatment of various respiratory diseases. There is little doubt that "inflammometry" will be a major step forward and will be useful in differentiating airway diseases and improving treatment. In the future, it is likely that smaller and more sensitive analyzers will extend the discriminatory value of exhaled breath analysis and that these techniques may be available to diagnose and monitor respiratory diseases in the general practice and home setting. More detailed insights into inflammatory processes can be obtained when the volatile and serum markers are considered together. The evaluation of $\mathrm{FE}_{\mathrm{NO}}$ reference values in the general population must consider dietary habits, age, weight, height, gender, asthma, atopy, smoking habits, current nasal and respiratory symptoms, and steroid assumption. The effect of various factors and different subpopulations on healthy subjects is also reported, in an effort to delineate future directions that need the establishment of EBC reference values.

\section{Conflict of Interests}

No conflict of interests was declared.

\section{References}

[1] R. Tardif, "The determination of acetaldehyde in exhaled breath," Novartis Foundation Symposium, vol. 285, pp. 125-133, 2007.

[2] C.-Y. Hahn, S.-Y. Huang, H.-C. Ko et al., "Acetaldehyde involvement in positive and negative alcohol expectancies in han Chinese persons with alcoholism," Archives of General Psychiatry, vol. 63, no. 7, pp. 817-823, 2006.

[3] K. Parameswaran, E. Pizzichini, M. M. Pizzichini, P. Hussack, A. Efthimiadis, and F. E. Hargreave, "Clinical judgement of airway inflammation versus sputum cell counts in patients with asthma," European Respiratory Journal, vol. 15, no. 3, pp. 486490, 2000.

[4] J. A. Nightingale, D. F. Rogers, and P. J. Barnes, "Effect of repeated sputum induction on cell counts in normal volunteers," Thorax, vol. 53, no. 2, pp. 87-90, 1998.
[5] S. A. Kharitonov and P. J. Barnes, "Clinical aspects of exhaled nitric oxide," European Respiratory Journal, vol. 16, no. 4, pp. 781-792, 2000.

[6] M. Phillips, J. Herrera, S. Krishnan, M. Zain, J. Greenberg, and R. N. Cataneo, "Variation in volatile organic compounds in the breath of normal humans," Journal of Chromatography B, vol. 729, no. 1-2, pp. 75-88, 1999.

[7] M. Phillips, "Breath tests in medicine," Scientific American, vol. 267, no. 1, pp. 74-79, 1992.

[8] W. Miekisch, J. K. Schubert, and G. F. E. Noeldge-Schomburg, "Diagnostic potential of breath analysis-focus on volatile organic compounds," Clinica Chimica Acta, vol. 347, no. 1-2, pp. 25-39, 2004.

[9] M. Phillips, R. N. Cataneo, R. Condos et al., "Volatile biomarkers of pulmonary tuberculosis in the breath," Tuberculosis, vol. 87, no. 1, pp. 44-52, 2007.

[10] J. E. Habel, E. H. Bursey, B.-S. Rho et al., "Structure of Rv1848 (UreA), the Mycobacterium tuberculosis urease $\gamma$ subunit," Acta Crystallographica Section F, vol. 66, no. 7, pp. 781-786, 2010.

[11] M. Maiga, A. Abaza, and W. R. Bishai, "Current tuberculosis diagnostic tools and role of urease breath test," Indian Journal of Medical Research, vol. 135, no. 5, pp. 731-736, 2012.

[12] L. Zhang, S. B. Mulrooney, A. F. K. Leung et al., "Inhibition of urease by bismuth(III): implications for the mechanism of action of bismuth drugs," BioMetals, vol. 19, no. 5, pp. 503-511, 2006.

[13] M. S. Jassal, G. G. Nedeltchev, J.-H. Lee et al., " ${ }^{13}$ [c]-urea breath test as a novel point-of-care biomarker for tuberculosis treatment and diagnosis," PLoS ONE, vol. 5, no. 8, Article ID e12451, 2010.

[14] M. Phillips, V. Basa-Dalay, J. Blais et al., "Point-of-care breath test for biomarkers of active pulmonary tuberculosis," Tuberculosis, vol. 92, no. 4, pp. 314-320, 2012.

[15] A. H. Kolk, J. J. van Berkel, M. M. Claassens et al., "Breath analysis as a potential diagnostic tool for tuberculosis," The International Journal of Tuberculosis and Lung Disease, vol. 16, no. 6, pp. 777-782, 2012.

[16] M. Phillips, V. Basa-Dalay, G. Bothamley et al., "Breath biomarkers of active pulmonary tuberculosis," Tuberculosis, vol. 90, no. 2, pp. 145-151, 2010.

[17] S. T. Chambers, A. Scott-Thomas, and M. Epton, "Developments in novel breath tests for bacterial and fungal pulmonary infection," Current Opinion in Pulmonary Medicine, vol. 18, no. 3, pp. 228-284, 2012.

[18] P. A. Tisdall, G. D. Roberts, and J. P. Anhalt, "Identification of clinical isolates of Mycobacteria with gas-liquid chromatography alone," Journal of Clinical Microbiology, vol. 10, no. 4, pp. 506-514, 1979.

[19] Y. Zhang, Y. Zhuang, Z. Liu, and J. Ruan, "Identification of twenty-eight species mycobacteria with their cellular fatty acids by capillary gas chromatography," Acta Microbiologica Sinica, vol. 31, no. 3, pp. 187-197, 1991.

[20] J. J. Parez, M. Fauville-Dufaux, J. L. Dossogne, E. De Hoffmann, and F. Pouthier, "Faster identification of mycobacteria using gas liquid and thin layer chromatography," European Journal of Clinical Microbiology and Infectious Diseases, vol. 13, no. 9, pp. 717-725, 1994.

[21] R. P. Manginell, A. S. Pimentel, C. D. Mowry et al., "Diagnostic potential of the pulsed discharged helium ionization detector (PDHID) for pathogenic Mycobacterial volatile biomarkers," Journal of Breath Research, vol. 7, no. 3, Article ID 037107, 2013. 
[22] S. Kwiatkowska, U. Szkudlarek, M. Łuczyńska, D. Nowak, and M. Zieba, "Elevated exhalation of hydrogen peroxide and circulating IL-18 in patients with pulmonary tuberculosis," Respiratory Medicine, vol. 101, no. 3, pp. 574-580, 2007.

[23] C.-H. Wang, C.-Y. Liu, H.-C. Lin, C.-T. Yu, K. F. Chung, and H.-P. Kuo, "Increased exhaled nitric oxide in active pulmonary tuberculosis due to inducible NO synthase upregulation in alveolar macrophages," European Respiratory Journal, vol. 11, no. 4, pp. 809-815, 1998.

[24] P. Jain, D. S. Thaler, M. Maiga et al., "Reporter phage and breath tests: emerging phenotypic assays for diagnosing active tuberculosis, antibiotic resistance, and treatment efficacy," Journal of Infectious Diseases, vol. 204, no. 4, pp. S1142-S1150, 2011.

[25] S. C. Van Beek, N. V. Nhung, D. N. Sy, P. J. Sterk, E. W. Tiemersma, and F. G. J. Cobelens, "Measurement of exhaled nitric oxide as a potential screening tool for pulmonary tuberculosis," International Journal of Tuberculosis and Lung Disease, vol. 15, no. 2, pp. 185-191, 2011.

[26] M. Phillips, R. N. Cataneo, A. R. C. Cummin et al., "Detection of lung cancer with volatile markers in the breath," Chest, vol. 123, no. 6, pp. 2115-2123, 2003.

[27] C.-Y. Liu, C.-H. Wang, T.-C. Chen, H.-C. Lin, C.-T. Yu, and H.-P. Kuo, "Increased level of exhaled nitric oxide and up-regulation of inducible nitric oxide synthase in patients with primary lung cancer," British Journal of Cancer, vol. 78, no. 4, pp. 534-541, 1998.

[28] M. Phillips, N. Altorki, J. H. M. Austin et al., "Prediction of lung cancer using volatile biomarkers in breath," Cancer Biomarkers, vol. 3, no. 2, pp. 95-109, 2007.

[29] M. Phillips, N. Altorki, J. H. M. Austin et al., "Detection of lung cancer using weighted digital analysis of breath biomarkers," Clinica Chimica Acta, vol. 393, no. 2, pp. 76-84, 2008.

[30] D. Poli, P. Carbognani, M. Corradi et al., "Exhaled volatile organic compounds in patients with non-small cell lung cancer: Cross sectional and nested short-term follow-up study," Respiratory Research, vol. 6, article 71, 2005.

[31] X. Chen, F. Xu, Y. Wang et al., "A study of the volatile organic compounds exhaled by lung cancer cells in vitro for breath diagnosis," Cancer, vol. 110, no. 4, pp. 835-844, 2007.

[32] M. Phillips, K. Gleeson, J. M. B. Hughes et al., "Volatile organic compounds in breath as markers of lung cancer: a crosssectional study," Lancet, vol. 353, no. 9168, pp. 1930-1933, 1999.

[33] N. Peled, M. Hakim, P. A. Bunn Jr et al., "Non-invasive breath analysis of pulmonary nodules," Journal of Thoracic Oncology, vol. 7, no. 10, pp. 1528-1533, 2012.

[34] Y. Wang, Y. Hu, D. Wang et al., "The analysis of volatile organic compounds biomarkers for lung cancer in exhaled breath, tissues and cell lines," Cancer Biomarkers, vol. 11, no. 4, pp. 129137, 2012.

[35] M. M. L. Steeghs, S. M. Cristescu, P. Munnik, P. Zanen, and F. J. M. Harren, "An off-line breath sampling and analysis method suitable for large screening studies," Physiological Measurement, vol. 28, no. 5, article 005, 2007.

[36] G. E. Carpagnano, A. Spanevello, C. Curci et al., "IL-2, TNF$\alpha$, and leptin: local versus systemic concentrations in NSCLC patients," Oncology Research, vol. 16, no. 8, pp. 375-381, 2007.

[37] G. E. Carpagnano, D. Lacedonia, G. P. Palladino et al., "Could exhaled ferritin and SOD be used as markers for lung cancer and prognosis prediction purposes?" European Journal of Clinical Investigation, vol. 42, no. 5, pp. 478-486, 2012.
[38] G. E. Carpagnano, M. P. Foschino-Barbaro, A. Spanevello et al., " $3 p$ microsatellite signature in exhaled breath condensate and tumor tissue of patients with lung cancer," American Journal of Respiratory and Critical Care Medicine, vol. 177, no. 3, pp. 337341, 2008.

[39] A. Ulanowska, E. Trawińska, P. Sawrycki, and B. Buszewski, "Chemotherapy control by breath profile with application of SPME-GC/MS method," Journal of Separation Science, vol. 35, no. 21, pp. 2908-2913, 2012.

[40] J. Kordiak, J. Szemraj, K. Hamara, P. Bialasiewicz, and D. Nowak, "Complete surgical resection of lung tumor decreases exhalation of mutated KRAS oncogene," Respiratory Medicine, vol. 106, no. 9, pp. 1293-1300, 2012.

[41] Y. Y. Broza, R. Kremer, U. Tisch, A. Gevorkyan, A. Shiban, and L. A. Best, "A nanomaterial-based breath test for short-term follow-up after lung tumor resection," Nanomedicine, vol. 9, no. 1, pp. 15-21, 2013.

[42] I. Enache, G. Noel, M. Y. Jeung et al., "Can exhaled NO fraction predict radiotherapy-induced lung toxicity in lung cancer patients," Radiation Oncology, vol. 7, p. 117, 2012.

[43] W. Carrol, W. Lenney, T. Wang, P. Španěl, A. Alcock, and D. Smith, "Detection of volatile compounds emitted by Pseudomonas aeruginosa using selected ion flow tube mass spectrometry," Pediatric Pulmonology, vol. 39, no. 5, pp. 452-456, 2005.

[44] W. A. Biernacki, S. A. Kharitonov, and P. J. Barnes, "Exhaled carbon monoxide in patients with lower respiratory tract infection," Respiratory Medicine, vol. 95, no. 12, pp. 1003-1005, 2001.

[45] C. G. Uasuf, A. Jatakanon, A. James, S. A. Kharitanov, N. M. Wilson, and P. J. Barnes, "Exhaled carbon monoxide in childhood asthma," Journal of Pediatrics, vol. 135, no. 5, pp. 569-574, 1999.

[46] M. Yamaya, K. Sekizawa, S. Ishizuka, M. Monma, K. Mizuta, and H. Sasaki, "Increased carbon monoxide in exhaled air of subjects with upper respiratory tract infections," American Journal of Respiratory and Critical Care Medicine, vol. 158, no. 1, pp. 311-314, 1998.

[47] T. G. Evans, K. Rasmussen, G. Wiebke, and J. B. Hibbs Jr., "Nitric oxide synthesis in patients with advanced HIV infection," Clinical and Experimental Immunology, vol. 97, no. 1, pp. 83-86, 1994.

[48] M. Haubitz, T. Busch, M. Gerlach et al., "Exhaled nitric oxide in patients with Wegener's granulomatosis," European Respiratory Journal, vol. 14, no. 1, pp. 113-117, 1999.

[49] S. G. Von Essen, L. A. Scheppers, R. A. Robbins, and K. J. Donham, "Respiratory tract inflammation in swine confinement workers studied using induced sputum and exhaled nitric oxide," Clinical Toxicology, vol. 36, no. 6, pp. 557-565, 1998.

[50] S. A. Kharitonov, D. Yates, and P. J. Barnes, "Increased nitric oxide in exhaled air of normal human subjects with upper respiratory tract infections," European Respiratory Journal, vol. 8, no. 2, pp. 295-297, 1995.

[51] C. M. Harrison and C. C. Andersen, "Exhaled breath measures of inflammation: are they useful in neonatal chronic lung disease?" Archives of Disease in Childhood, vol. 90, no. 1, pp. F6F10, 2005.

[52] J. O. N. Lundberg, J. Palm, and K. Alving, "Nitric oxide but not carbon monoxide is continuously released in the human nasal airways," European Respiratory Journal, vol. 20, no. 1, pp. 100$103,2002$.

[53] M. Syhre, J. M. Scotter, and S. T. Chambers, "Investigation into the production of 2-Pentylfuran by Aspergillus fumigatus 
and other respiratory pathogens in vitro and human breath samples," Medical Mycology, vol. 46, no. 3, pp. 209-215, 2008.

[54] J. Julak, E. Stranska, V. Rosova, and A. Dohnalova, "Chemical analysis of bronchoalveolar lavage in diagnostics of pneumonia," Clinical Microbiology and Infectious Diseases, vol. 10, pp. 279-283, 2004.

[55] A. Sandrini, A. R. Johnson, P. S. Thomas, and D. H. Yates, "Fractional exhaled nitric oxide concentration is increased in asbestosis and pleural plaques," Respirology, vol. 11, no. 3, pp. 325-329, 2006.

[56] H. Lehtonen, P. Oksa, L. Lehtimäki et al., "Increased alveolar nitric oxide concentration and high levels of leukotriene B4 and 8-isoprostane in exhaled breath condensate in patients with asbestosis," Thorax, vol. 62, no. 7, pp. 602-607, 2007.

[57] S. A. Kharitonov and P. J. Barnes, "Biomarkers of some pulmonary diseases in exhaled breath," Biomarkers, vol. 7, no. 1, pp. 1-32, 2002.

[58] D. Pelclova, Z. Fenclova, P. Kacer et al., "8-isoprostane and leukotrienes in exhaled breath condensate in Czech subjects with silicosis," Industrial Health, vol. 45, no. 6, pp. 766-774, 2007.

[59] Z. Ziętkowski and A. Bodzenta-łukaszyk, "Exhaled nitric oxide (NO) in patients with respiratory tract diseases," Polski Merkuriusz Lekarski, vol. 16, no. 92, pp. 115-118, 2004.

[60] L. Lehtimäki, V. Turjanmaa, H. Kankaanranta, S. Saarelainen, P. Hahtola, and E. Moilanen, "Increased bronchial nitric oxide production in patients with asthma measured with a novel method of different exhalation flow rates," Annals of Medicine, vol. 32, no. 6, pp. 417-423, 2000.

[61] J. Galli, P. Montuschi, G. C. Passali, M. Laruffa, C. Parrilla, and G. Paludetti, "Exhaled nitric oxide measurement in patients affected by nasal polyposis," Otolaryngol Head Neck Surg, vol. 147, no. 2, pp. 351-356, 2012.

[62] K. Basu, A. Nair, P. A. Williamson, S. Mukhopadhyay, and B. J. Lipworth, "Airway and systemic effects of soluble and suspension formulations of nebulized budesonide in asthmatic children," Annals of Allergy, Asthma and Immunology, vol. 103, no. 5, pp. 436-441, 2009.

[63] W. Zetterquist, H. Marteus, M. Johannesson et al., "Exhaled carbon monoxide is not elevated in patients with asthma or cystic fibrosis," European Respiratory Journal, vol. 20, no. 1, pp. 92-99, 2002.

[64] I. Horváth, L. E. Donnelly, A. Kiss, P. Paredi, S. A. Kharitonov, and P. J. Barnes, "Raised levels of exhaled carbon monoxide are associated with an increased expression of heme oxygenase-1 in airway macrophages in asthma: a new marker of oxidative stress," Thorax, vol. 53, no. 8, pp. 668-672, 1998.

[65] C. O. Olopade, M. Zakkar, W. I. Swedler, and I. Rubinstein, "Exhaled pentane levels in acute asthma," Chest, vol. 111, no. 4, pp. 862-865, 1997.

[66] P. Paredi, S. A. Kharitonov, and P. J. Barnes, "Elevation of exhaled ethane concentration in asthma," American Journal of Respiratory and Critical Care Medicine, vol. 162, no. 4 I, pp. 1450-1454, 2000.

[67] S. Dragonieri, R. Schot, B. J. A. Mertens et al., "An electronic nose in the discrimination of patients with asthma and controls," The Journal of Allergy and Clinical Immunology, vol. 120, no. 4, pp. 856-862, 2007.

[68] J. F. Hunt, E. Erwin, L. Palmer et al., "Expression and activity of pH-regulatory glutaminase in the human airway epithelium," American Journal of Respiratory and Critical Care Medicine, vol. 165, no. 1, pp. 101-107, 2002.
[69] P. Montuschi, S. A. Kharitonov, G. Ciabattoni, and P. J. Barnes, "Exhaled leukotrienes and prostaglandins in COPD," Thorax, vol. 58, no. 7, pp. 585-588, 2003.

[70] P. Montuschi and P. J. Barnes, "Exhaled leukotrienes and prostaglandins in asthma," The Journal of Allergy and Clinical Immunology, vol. 109, no. 4, pp. 615-620, 2002.

[71] I. Rahman and F. Kelly, "Biomarkers in breath condensate: a promising new non-invasive technique in free radical research," Free Radical Research, vol. 37, no. 12, pp. 1253-1266, 2003.

[72] Z. Csoma, S. A. Kharitonov, B. Balint, A. Bush, N. M. Wilson, and P. J. Barnes, "Increased leukotrienes in exhaled breath condensate in childhood asthma," American Journal of Respiratory and Critical Care Medicine, vol. 166, no. 10, pp. 1345-1349, 2002.

[73] T. Hanazawa, S. A. Kharitonov, and P. J. Barnes, "Increased nitrotyrosine in exhaled breath condensate of patients with asthma," American Journal of Respiratory and Critical Care Medicine, vol. 162, no. 4 I, pp. 1273-1276, 2000.

[74] G. Becher, K. Winsel, E. Beck, C. Neubauer, and E. Stresemann, "Breathing condensate as noninvasive measure for mediators from the lower airways," Pneumologie, vol. 51, no. 2, pp. 456459, 1997.

[75] T. Hanazawa, S. A. Kharitonov, W. Oldfield, A. B. Kay, and P. J. Barnes, "Nitrotyrosine and cystenyl leukotrienes in breath condensates are increased after withdrawal of steroid treatment in patients with asthma," American Journal of Respiratory and Critical Care Medicine, vol. 161, p. A919, 2000.

[76] W. A. Biernacki, S. A. Kharitonov, and P. J. Barnes, "Increased leukotriene B4 and 8-isoprostane in exhaled breath condensate of patients with exacerbations of COPD," Thorax, vol. 58, no. 4, pp. 294-298, 2003.

[77] M. Mikami, C. G. Llewellyn-Jones, D. Bayley, S. L. Hill, and R. A. Stockley, "The chemotactic activity of sputum from patients with bronchiectasis," American Journal of Respiratory and Critical Care Medicine, vol. 157, no. 3, pp. 723-728, 1998.

[78] Y. Tochino, H. Kanazawa, Y. Ichimaru, K. Asai, S. Kyoh, and K. Hirata, "N ${ }^{\varepsilon}$-(carboxymethyl)lysine, a major advanced glycation end product in exhaled breath condensate as a biomarker of small airway involvement in asthma," Journal of Asthma, vol. 44, no. 10, pp. 861-866, 2007.

[79] F. W. S. Ko, C. Y. K. Lau, T. F. Leung et al., "Exhaled breath condensate levels of eotaxin and macrophage-derived chemokine in stable adult asthma patients," Clinical and Experimental Allergy, vol. 36, no. 1, pp. 44-51, 2006.

[80] P. Montuschi, F. Macagno, P. Parente et al., "Effects of cyclooxygenase inhibition on exhaled eicosanoids in patients with COPD," Thorax, vol. 60, no. 10, pp. 827-833, 2005.

[81] S. V. Culpitt, P. Paredi, S. A. Kharitonov, and P. J. Barnes, "Exhaled carbon monoxide is increased in COPD patients regardless of their smoking habit," American Journal of Respiratory and Critical Care Medicine, vol. 157, p. A787, 1998.

[82] P. Paredi, S. A. Kharitonov, D. Leak, S. Ward, D. Cramer, and P. J. Barnes, "Exhaled ethane, a marker of lipid peroxidation, is elevated chronic obstructive pulmonary disease," American Journal of Respiratory and Critical Care Medicine, vol. 162, no. 2 I, pp. 369-373, 2000.

[83] W. M. Foster, L. Jiang, P. T. Stetkiewicz, and T. H. Risby, "Breath isoprene: temporal changes in respiratory output after exposure to ozone," Journal of Applied Physiology, vol. 80, no. 2, pp. 706710, 1996.

[84] K. N. Jeejeebhoy, "In vivo breath alkane as an index of lipid peroxidation," Free Radical Biology and Medicine, vol. 10, no. 34, pp. 191-193, 1991. 
[85] B.-K. Q. Do, H. S. Garewal, N. C. Clements Jr., Y.-M. Peng, and M. P. Habib, "Exhaled ethane and antioxidant vitamin supplements in active smokers," Chest, vol. 110, no. 1, pp. 159-164, 1996.

[86] C. O. Olopade, J. A. Christon, M. Zakkar et al., "Exhaled pentane and nitric oxide levels in patients with obstructive sleep apnea," Chest, vol. 111, no. 6, pp. 1500-1504, 1997.

[87] G. E. Carpagnano, A. Spanevello, R. Sabato, A. Depalo, V. Turchiarelli, and M. P. Foschino Barbaro, "Exhaled pH, exhaled nitric oxide, and induced sputum cellularity in obese patients with obstructive sleep apnea syndrome," Translational Research, vol. 151, no. 1, pp. 45-50, 2008.

[88] P. Montuschi, D. Currò, E. Ragazzoni, P. Preziosi, and G. Ciabattoni, "Anaphylaxis increases 8-iso-prostaglandin $\mathrm{F}(2 \alpha)$ release from guinea-pig lung in vitro," European Journal of Pharmacology, vol. 365, no. 1, pp. 59-64, 1999.

[89] P. Montuschi, M. Corradi, G. Ciabattoni, J. Nightingale, S. A. Kharitonov, and P. J. Barnes, "Increased 8-isoprostane, a marker of oxidative stress, in exhaled condensate of asthma patients," American Journal of Respiratory and Critical Care Medicine, vol. 160, no. 1, pp. 216-220, 1999.

[90] L. G. Wood, P. G. Gibson, and M. L. Garg, "Biomarkers of lipid peroxidation, airway inflammation and asthma," European Respiratory Journal, vol. 21, no. 1, pp. 177-186, 2003.

[91] I. Romieu, A. Barraza-Villarreal, C. Escamilla-Nuñez et al., "Exhaled breath malondialdehyde as a marker of effect of exposure to air pollution in children with asthma," Journal of Allergy and Clinical Immunology, vol. 121, no. 4, pp. 903-e6, 2008.

[92] A. Davidsson, M. Söderström, K. N. Sjöswärd, and B. Schmekel, "Chlorine in breath condensate-a measure of airway affection in pollinosis?" Respiration, vol. 74, no. 2, pp. 184-191, 2007.

[93] S. A. Kharitonov, L. E. Donnelly, P. Montuschi, M. Corradi, J. V. Collins, and P. J. Barnes, "Dose-dependent onset and cessation of action of inhaled budesonide on exhaled nitric oxide and symptoms in mild asthma," Thorax, vol. 57, no. 10, pp. 889-896, 2002.

[94] P. Montuschi, J. V. Collins, G. Ciabattoni et al., "Exhaled 8isoprostane as an in vivo biomarker of lung oxidative stress in patients with COPD and healthy smokers," American Journal of Respiratory and Critical Care Medicine, vol. 162, no. 3 I, pp. 1175$1177,2000$.

[95] G. E. Carpagnano, O. Resta, M. P. Foschino-Barbaro et al., "Exhaled Interleukine-6 and 8-isoprostane in chronic obstructive pulmonary disease: effect of carbocysteine lysine salt monohydrate (SCMC-Lys)," European Journal of Pharmacology, vol. 505, no. 1-3, pp. 169-175, 2004.

[96] G. E. Carpagnano, S. A. Kharitonov, M. P. Foschino-Barbaro, O. Resta, E. Gramiccioni, and P. J. Barnes, "Supplementary oxygen in healthy subjects and those with COPD increases oxidative stress and airway inflammation," Thorax, vol. 59, no. 12, pp. 1016-1019, 2004.

[97] F. W. S. Ko, C. Y. K. Lau, T. F. Leung, G. W. K. Wong, C. W. K. Lam, and D. S. C. Hui, "Exhaled breath condensate levels of 8-isoprostane, growth related oncogene $\alpha$ and monocyte chemoattractant protein-1 in patients with chronic obstructive pulmonary disease," Respiratory Medicine, vol. 100, no. 4, pp. 630-638, 2006.

[98] D. Makris, E. Paraskakis, P. Korakas et al., "Exhaled breath condensate 8-isoprostane, clinical parameters, radiological indices and airway inflammation in COPD," Respiration, vol. 75, no. 2 , pp. 138-144, 2008.
[99] C. Gessner, S. Hammerschmidt, H. Kuhn et al., "Breath condensate nitrite correlates with hyperinflation in chronic obstructive pulmonary disease," Respiratory Medicine, vol. 101, no. 11, pp. 2271-2278, 2007.

[100] M. Malerba and M. MontuschiP., "Non-invasive biomarkers of lung inflammation in smoking subjects," Current Medicinal Chemistry, vol. 19, no. 2, pp. 187-196, 2012.

[101] M. Corradi, I. Rubinstein, R. Andreoli et al., "Aldehydes in exhaled breath condensate of patients with chronic obstructive pulmonary disease," American Journal of Respiratory and Critical Care Medicine, vol. 167, no. 10, pp. 1380-1386, 2003.

[102] M. Corradi, P. Montuschi, L. E. Donnelly, A. Pesci, S. A. Kharitonov, and P. J. Barnes, "Increased nitrosothiols in exhaled breath condensate in inflammatory airway diseases," American Journal of Respiratory and Critical Care Medicine, vol. 163, no. 4, pp. 854-858, 2001.

[103] C. Gessner, R. Scheibe, M. Wötzel et al., "Exhaled breath condensate cytokine patterns in chronic obstructive pulmonary disease," Respiratory Medicine, vol. 99, no. 10, pp. 1229-1240, 2005.

[104] P. N. R. Dekhuijzen, K. K. H. Aben, I. Dekker et al., "Increased exhalation of hydrogen peroxide in patients with stable and unstable chronic obstructive pulmonary disease," American Journal of Respiratory and Critical Care Medicine, vol. 154, no. 3 I, pp. 813-816, 1996.

[105] C. Schumann, K. Triantafilou, S. Krueger et al., "Detection of erythropoietin in exhaled breath condensate of nonhypoxic subjects using a multiplex bead array," Mediators of Inflammation, vol. 2006, Article ID 18061, 5 pages, 2006.

[106] A. Mutti, M. Corradi, M. Goldoni, M. V. Vettori, A. Bernard, and P. Apostoli, "Exhaled metallic elements and serum pneumoproteins in asymptomatic smokers and patients with COPD or asthma," Chest, vol. 129, no. 5, pp. 1288-1297, 2006.

[107] P. Paredi, P. L. Shah, P. Montuschi et al., "Increased carbon monoxide in exhaled air of patients with cystic fibrosis," Thorax, vol. 54, no. 10, pp. 917-920, 1999.

[108] S. A. Kharitonov, M. Corradi, L. van Rensen et al., "Exhaled 8isoprostane as a new non-invasive biomarker of oxidative stress in cystic fibrosis," Thorax, vol. 55, no. 3, pp. 205-209, 2000.

[109] P. Paredi, S. A. Kharitonov, D. Leak et al., "Exhaled ethane is elevated in cystic fibrosis and correlates with carbon monoxide levels and airway obstruction," American Journal of Respiratory and Critical Care Medicine, vol. 161, no. 4 I, pp. 1247-1251, 2000.

[110] L. P. Ho, J. A. Innes, and A. P. Greening, "Nitrite levels in breath condensate of patients with cystic fibrosis is elevated in contrast to exhaled nitric oxide," Thorax, vol. 53, no. 8, pp. 680-684, 1998.

[111] S. J. Linnane, V. M. Keatings, C. M. Costello et al., "Total sputum nitrate plus nitrite is raised during acute pulmonary infection in cystic fibrosis," American Journal of Respiratory and Critical Care Medicine, vol. 158, no. 1, pp. 207-212, 1998.

[112] B. Balint, L. E. Donnelly, T. Hanazawa, S. A. Kharitonov, and P. J. Barnes, "Increased nitric oxide metabolites in exhaled breath condensate after exposure to tobacco smoke," Thorax, vol. 56, no. 6, pp. 456-461, 2001.

[113] K. L. Jones, A. H. Hegab, B. C. Hillman et al., "Elevation of nitrotyrosine and nitrate concentrations in cystic fibrosis sputum," Pediatric Pulmonology, vol. 30, pp. 79-85, 2000.

[114] M. Corradi, P. Montuschi, L. E. Donnelly, M. E. Hodson, S. A. Kharitonov, and P. J. Barnes, "Nitrosothiols and nitrite in exhaled breath condensate of patients with cystic fibrosis," American Journal of Respiratory and Critical Care Medicine, vol. 159, p. A682, 1999. 
[115] H. Grasemann, B. Gaston, K. Fang, K. Paul, and F. Ratjen, "Decreased levels of nitrosothiols in the lower airways of patients with cystic fibrosis and normal pulmonary function," The Journal of Pediatrics, vol. 135, no. 6, pp. 770-772, 1999.

[116] S. Celio, H. Troxler, S. S. Durka et al., "Free 3-nitrotyrosine in exhaled breath condensates of children fails as a marker for oxidative stress in stable cystic fibrosis and asthma," Nitric Oxide, vol. 15, no. 3, pp. 226-232, 2006.

[117] M. Barker, M. Hengst, J. Schmid et al., "Volatile organic compounds in the exhaled breath of young patients with cystic fibrosis," European Respiratory Journal, vol. 27, no. 5, pp. 929936, 2006.

[118] C. M. H. H. T. Robroeks, Q. Jöbsis, J. G. M. C. Damoiseaux et al., "Cytokines in exhaled breath condensate of children with asthma and cystic fibrosis," Annals of Allergy, Asthma and Immunology, vol. 96, no. 2, pp. 349-355, 2006.

[119] A. Bodini, C. D’Orazio, D. G. Peroni et al., "IL-8 and pH values in exhaled condensate after antibiotics in cystic fibrosis children," International Journal of Immunopathology and Pharmacology, vol. 20, no. 3, pp. 467-472, 2007.

[120] C. Coop, L. L. Hagan, and J. P. Dice, "Exhaled breath condensate $\mathrm{pH}$ in the evaluation of asthma," Allergy and Asthma Proceedings, vol. 29, no. 1, pp. 51-54, 2008.

[121] R. Accordino, A. Visentin, A. Bordin et al., "Long-term repeatability of exhaled breath condensate $\mathrm{pH}$ in asthma," Respiratory Medicine, vol. 102, no. 3, pp. 377-381, 2008.

[122] Y. Bujanover, Y. Peled, and H. Blau, "Methane production in patients with cystic fibrosis," Journal of Pediatric Gastroenterology and Nutrition, vol. 6, no. 3, pp. 377-380, 1987.

[123] J. L. Fridge, C. Conrad, L. Gerson, R. O. Castillo, and K. Cox, "Risk factors for small bowel bacterial overgrowth in cystic fibrosis," Journal of Pediatric Gastroenterology and Nutrition, vol. 44, no. 2, pp. 212-218, 2007.

[124] R. Skiepko, Z. Zietkowski, M. M. Tomasiak, and A. BodzentaLukaszyk, "Exhaled breath condensate in the assessment of airway inflammation," Przegląd Lekarski, vol. 63, no. 12, pp. 1321-1325, 2006.

[125] J. Hunt, "Exhaled breath condensate: an evolving tool for noninvasive evaluation of lung disease," The Journal of Allergy and Clinical Immunology, vol. 110, no. 1, pp. 28-34, 2002.

[126] S. A. Kharitonov and P. J. Barnes, "Exhaled markers of inflammation," Current Opinion in Allergy and Clinical Immunology, vol. 1, no. 3, pp. 217-224, 2001.

[127] B. Buszewski, M. Kesy, T. Ligor, and A. Amann, "Human exhaled air analytics: biomarkers of diseases," Biomedical Chromatography, vol. 21, no. 6, pp. 553-566, 2007.

[128] S. Kanoh, H. Kobayashi, and K. Motoyoshi, "Exhaled ethane: an in vivo biomarker of lipid peroxidation in interstitial lung diseases," Chest, vol. 128, no. 4, pp. 2387-2392, 2005.

[129] A. Van Muylem, C. Knoop, and M. Estenne, "Early detection of chronic pulmonary allograft dysfunction by exhaled biomarkers," American Journal of Respiratory and Critical Care Medicine, vol. 175, no. 7, pp. 731-736, 2007.

[130] K. Czebe, T. Kullmann, E. Csiszer, E. Barat, I. Horvath, and B. Antus, "Variability of exhaled breath condensate $\mathrm{pH}$ in lung transplant recipients," Respiration, vol. 75, no. 3, pp. 322-327, 2008.

[131] M. A. E. Lärstad, K. Torén, B. Bake, and A.-C. Olin, "Determination of ethane, pentane and isoprene in exhaled air-effects of breath-holding, flow rate and purified air," Acta Physiologica, vol. 189, no. 1, pp. 87-98, 2007.
[132] M. Lärstad, A.-S. Söderling, K. Caidahl, and A.-C. Olin, "Selective quantification of free 3-nitrotyrosine in exhaled breath condensate in asthma using gas chromatography/tandem mass spectrometry," Nitric Oxide, vol. 13, no. 2, pp. 134-144, 2005.

[133] A. Emelyanov, G. Fedoseev, A. Abulimity et al., "Elevated concentrations of exhaled hydrogen peroxide in asthmatic patients," Chest, vol. 120, no. 4, pp. 1136-1139, 2001.

[134] I. Horvath, S. Loukides, T. Wodehouse, S. A. Kharitonov, P. J. Cole, and P. J. Barnes, "Increased levels of exhaled carbon monoxide in bronchiectasis: a new marker of oxidative stress," Thorax, vol. 53, no. 10, pp. 867-870, 1998.

[135] K. W. Tsang, R. Leung, P. C.-W. Fung et al., "Exhaled and sputum nitric oxide in bronchiectasis: correlation with clinical parameters," Chest, vol. 121, no. 1, pp. 88-94, 2002.

[136] J. D. Antuni, S. Ward, D. S. Cramer, S. A. Kharitonov, and P. J. Barnes, "Uptake and elimination of exhaled carbon monoxide in patients with interstitial lung disease is related to the degree ofimpairment of carbon monoxide diffusion capacity," American Journal of Respiratory and Critical Care Medicine, vol. 159, p. A86, 1999.

[137] S. A. Kharitonov, J. B. Cailes, C. M. Black, R. M. Du Bois, and P. J. Barnes, "Decreased nitric oxide in the exhaled air of patients with systemic sclerosis with pulmonary hypertension," Thorax, vol. 52, no. 12, pp. 1051-1055, 1997.

[138] G. Rolla, P. Colagrande, E. Scappaticci et al., "Exhaled nitric oxide in systemic sclerosis: relationships with lung involvement and pulmonary hypertension," Journal of Rheumatology, vol. 27, no. 7, pp. 1693-1698, 2000.

[139] A. Giaid and D. Saleh, "Reduced expression of endothelial nitric oxide synthase in the lungs of patients with pulmonary hypertension," The New England Journal of Medicine, vol. 333, no. 4, pp. 214-221, 1995.

[140] S. M. Black, J. R. Fineman, R. H. Steinhorn, J. Bristow, and S. J. Soifer, "Increased endothelial NOS in lambs with increased pulmonary blood flow and pulmonary hypertension," American Journal of Physiology, vol. 275, no. 5, pp. H1643-H1651, 1998.

[141] R. C. Tyler, M. Muramatsu, S. H. Abman et al., "Variable expression of endothelial no synthase in three forms of rat pulmonary hypertension," American Journal of Physiology, vol. 276, no. 2, pp. L297-L303, 1999.

[142] A. D. Everett, T. D. Le Cras, C. Xue, and R. A. Johns, "eNOS expression is not altered in pulmonary vascular remodeling due to increased pulmonary blood flow," American Journal of Physiology, vol. 274, no. 6, pp. L1058-L1065, 1998.

[143] D. Saleh, P. J. Barnes, and A. Giaid, "Increased production of the potent oxidant peroxynitrite in the lungs of patients with idiopathic pulmonary fibrosis," American Journal of Respiratory and Critical Care Medicine, vol. 155, no. 5, pp. 1763-1769, 1997.

[144] P. Paredi, S. A. Kharitonov, S. Loukides, P. Pantelidis, R. M. Du Bois, and P. J. Barnes, "Exhaled nitric oxide is increased in active fibrosing alveolitis," Chest, vol. 115, no. 5, pp. 1352-1356, 1999.

[145] D. M. O’donnell, J. Moynihan, G. A. Finlay et al., "Exhaled nitric oxide and bronchoalveolar lavage nitrite/nitrate in active pulmonary sarcoidosis," American Journal of Respiratory and Critical Care Medicine, vol. 156, no. 6, pp. 1892-1896, 1997.

[146] Y. P. Moodley, R. Chetty, and U. G. Lalloo, "Nitric oxide levels in exhaled air and inducible nitric oxide synthase immunolocalization in pulmonary sarcoidosis," European Respiratory Journal, vol. 14, no. 4, pp. 822-827, 1999. 
[147] A. Rozy, J. Czerniawska, A. Stępniewska et al., "Inflammatory markers in the exhaled breath condensate of patients with pulmonary sacroidosis," Journal of Physiology and Pharmacology, vol. 57, no. 4, pp. 335-340, 2006.

[148] W. J. Piotrowski, A. Antczak, J. Marczak, A. Nawrocka, Z. Kurmanowska, and P. Górski, "Eicosanoids in exhaled breath condensate and BAL fluid of patients with sarcoidosis," Chest, vol. 132, no. 2, pp. 589-596, 2007.

[149] P. J. Montuschi, "LC/MS/MS analysis of leukotriene $B_{4}$ and other eicosanoids in exhaled breath condensate for assessing lung inflammation," Journal of Chromatography B, vol. 877, no. 13, pp. 1272-1280, 2009.

[150] P. Montuschi, D. Paris, D. Melck et al., "NMR spectroscopy metabolomic profiling of exhaled breath condensate in patients with stable and unstable cystic fibrosis," Thorax, vol. 67, no. 3 , pp. 222-228, 2012.

[151] Z. L. Borrill, K. Roy, and D. Singh, "Exhaled breath condensate biomarkers in COPD," European Respiratory Journal, vol. 32, no. 2, pp. 472-486, 2008.

[152] S. Carraro, S. Rezzi, F. Reniero et al., "Metabolomics applied to exhaled breath condensate in childhood asthma," American Journal of Respiratory and Critical Care Medicine, vol. 175, no. 10, pp. 986-990, 2007.

[153] J. Scholpp, J. K. Schubert, W. Miekisch, and K. Geiger, "Breath markers and soluble lipid peroxidation markers in critically III patients," Clinical Chemistry and Laboratory Medicine, vol. 40, no. 6, pp. 587-594, 2002.

[154] C. Turner, P. Španěl, and D. Smith, "A longitudinal study of ammonia, acetone and propanol in the exhaled breath of 30 subjects using selected ion flow tube mass spectrometry, SIFTMS," Physiological Measurement, vol. 27, no. 4, pp. 321-337, 2006.

[155] S. T. Senthilmohan, D. B. Milligan, M. J. McEwan, C. G. Freeman, and P. F. Wilson, "Quantitative analysis of trace gases of breath during exercise using the new SIFT-MS technique," Redox Report, vol. 5, no. 2-3, pp. 151-153, 2000.

[156] J. K. Schubert, W. P. E. Müller, A. Benzing, and K. Geiger, "Application of a new method for analysis of exhaled gas in critically ill patients," Intensive Care Medicine, vol. 24, no. 5, pp. 415-421, 1998.

[157] Y. Ishibe, R. Liu, J. Hirosawa, K. Kawamura, K. Yamasaki, and N. Saito, "Exhaled nitric oxide level decreases after cardiopulmonary bypass in adult patients," Critical Care Medicine, vol. 28, no. 12, pp. 3823-3827, 2000.

[158] E. D. Moloney, S. E. Mumby, R. Gajdocsi et al., "Exhaled breath condensate detects markers of pulmonary inflammation after cardiothoracic surgery," American Journal of Respiratory and Critical Care Medicine, vol. 169, no. 1, pp. 64-69, 2004.

[159] S. A. Kharitonov and P. J. Barnes, "Exhaled markers of pulmonary disease," American Journal of Respiratory and Critical Care Medicine, vol. 163, no. 7, pp. 1693-1722, 2001.

[160] K. W. Garey, M. M. Neuhauser, A. L. Rafice, R. A. Robbins, L. H. Danziger, and I. Rubinstein, "Protein, nitrite/nitrate, and cytokine concentration in exhaled breath condensate of young smokers," American Journal of Respiratory and Critical Care Medicine, vol. 161, p. A175, 2000.

[161] T. Tsuburai, H. Mita, N. Tsurikisawa et al., "The relationship between cysteinyl leukotriene in exhaled breath condensate and the severity of asthma in adult asthmatics in Japan," Japanese Journal of Allergology, vol. 57, no. 2, pp. 121-129, 2008.

[162] A. V. Emel'ianov, M. A. Petrova, O. V. Lavrova, L. I. Guleva, A. F. Dolgodvorov, and G. B. Fedoseev, "Disorders in mineral metabolism at different stages of the development of bronchial asthma," Terapevticheskii Arkhiv, vol. 67, no. 8, pp. 45-47, 1995.

[163] B. G. Stone, T. J. Besse, W. C. Duane, C. D. Evans, and E. G. DeMaster, "Effect of regulating cholesterol biosynthesis on breath isoprene excretion in men," Lipids, vol. 28, no. 8, pp. 705708, 1993.

[164] C. M. F. Kneepkens, C. Ferreira, G. Lepage, and C. C. Roy, "The hydrocarbon breath test in the study of lipid peroxidation: principles and practice," Clinical and Investigative Medicine, vol. 15, no. 2, pp. 163-186, 1992.

[165] Breath test for the detection of various diseases-Patent 6540691. Summary of the invention, p. 15, http://www.freepatentsonline .com/6540691.html, 2008.

[166] S. A. Kharitonov, "Exhaled markers of inflammatory lung diseases: Ready for routine monitoring?" Swiss Medical Weekly, vol. 134, no. 13-14, pp. 175-192, 2004.

[167] L. M. Van Den Toorn, J.-B. Prins, S. E. Overbeek, H. C. Hoogsteden, and J. C. De Jongste, "Adolescents in clinical remission of atopic asthma have elevated exhaled nitric oxide levels and bronchial hyperresponsiveness," American Journal of Respiratory and Critical Care Medicine, vol. 162, no. 3 I, pp. 953957, 2000.

[168] S. A. Kharitonov, D. H. Yates, and P. J. Barnes, "Inhaled glucocorticoids decrease nitric oxide in exhaled air of asthmatic patients," American Journal of Respiratory and Critical Care Medicine, vol. 153, no. 1, pp. 454-457, 1996.

[169] P. F. G. Gannon, J. Belcher, C. F. A. Pantin, and P. S. Burge, "The effect of patient technique and training on the accuracy of selfrecorded peak expiratory flow," European Respiratory Journal, vol. 14, no. 1, pp. 28-31, 1999.

[170] S. A. Kharitonov, F. Gonio, C. Kelly, S. Meah, and P. J. Barnes, "Reproducibility of exhaled nitric oxide measurements in healthy and asthmatic adults and children," European Respiratory Journal, vol. 21, no. 3, pp. 433-438, 2003.

[171] P. E. Silkoff, "Recommendations for standardized procedures for the online and offline measurement of exhaled lower respiratory nitric oxide and nasal nitric oxide in adults and children," American Journal of Respiratory and Critical Care Medicine, vol. 160, no. 6, pp. 2104-2117, 1999.

[172] S. A. Kharitonov and P. J. Barnes, "Does exhaled nitric oxide reflect asthma control? Yes, it does!," American Journal of Respiratory and Critical Care Medicine, vol. 164, no. 5, pp. 727-728, 2001.

[173] A.-C. Olin, B. Bake, and K. Torén, "Fraction of exhaled nitric oxide at $50 \mathrm{~mL} / \mathrm{s}$ : reference values for adult lifelong neversmokers," Chest, vol. 131, no. 6, pp. 1852-1856, 2007.

[174] M. Olivieri, M. Malerba, G. Talamini, and M. Corradi, "Reference values for exhaled nitric oxide in the general population," Chest, vol. 133, no. 3, pp. 831-832, 2008.

[175] American Thoracic Society; European Respiratory Society, "ATS/ERS recommendations for standardized procedures for online and offline measurement of exhaled lower respiratory nitric oxide and nasal nitric oxide," American Journal of Respiratory and Critical Care Medicine, vol. 171, no. 8, pp. 912-930, 2005.

[176] M. Olivieri, G. Talamini, M. Corradi et al., "Reference values for exhaled nitric oxide (reveno) study," Respiratory Research, vol. 7, article 94, 2006.

[177] G. Rolla, G. Guida, E. Heffler et al., "Diagnostic classification of persistent rhinitis and its relationship to exhaled nitric oxide and asthma: a clinical study of a consecutive series of patients," Chest, vol. 131, no. 5, pp. 1345-1352, 2007. 
[178] S. Vahlkvist, M. Sinding, K. Skamstrup, and H. Bisgaard, "Daily home measurements of exhaled nitric oxide in asthmatic children during natural birch pollen exposure," Journal of Allergy and Clinical Immunology, vol. 117, no. 6, pp. 1272-1276, 2006.

[179] J. Travers, S. Marsh, S. Aldington et al., "Reference ranges for exhaled nitric oxide derived from a random community survey of adults," American Journal of Respiratory and Critical Care Medicine, vol. 176, no. 3, pp. 238-242, 2007.

[180] A.-C. Olin, A. Rosengren, D. S. Thelle, L. Lissner, B. Bake, and K. Torén, "Height, age, and atopy are associated with fraction of exhaled nitric oxide in a large adult general population sample," Chest, vol. 130, no. 5, pp. 1319-1325, 2006.

[181] F. Cardinale, R. Tesse, C. Fucilli et al., "Correlation between exhaled nitric oxide and dietary consumption of fats and antioxidants in children with asthma," The Journal of Allergy and Clinical Immunology, vol. 119, no. 5, pp. 1268-1270, 2007.

[182] K. Kostikas, A. I. Papaioannou, K. Tanou, A. Koutsokera, M. Papala, and K. I. Gourgoulianis, "Portable exhaled nitric oxide as a screening tool for asthma in young adults during pollen season," Chest, vol. 133, no. 4, pp. 906-913, 2008.

[183] D. H. Yates, S. A. Kharitonov, P. S. Thomas, and P. J. Barnes, "Endogenous nitric oxide is decreased in asthmatic patients by an inhibitor of inducible nitric oxide synthase," American Journal of Respiratory and Critical Care Medicine, vol. 154, no. 1, pp. 247-250, 1996.

[184] C. M. F. Kneepkens, G. Lepage, and C. C. Roy, "The potential of the hydrocarbon breath test as a measure of lipid peroxidation," Free Radical Biology and Medicine, vol. 17, no. 6, pp. 127-160, 1994.

[185] M. Lärstad, C. Loh, G. Ljungkvist, A.-C. Olin, and K. Torén, "Determination of ethane, pentane and isoprene in exhaled air using a multi-bed adsorbent and end-cut gas-solid chromatography," Analyst, vol. 127, no. 11, pp. 1440-1445, 2002.

[186] E. Baraldi, S. Carraro, R. Alinovi et al., "Cysteinyl leukotrienes and 8-isoprostane in exhaled breath condensate of children with asthma exacerbations," Thorax, vol. 58, no. 6, pp. 505-509, 2003.

[187] Z. Csoma, A. Bush, N. M. Wilson et al., "Nitric oxide metabolites are not reduced in exhaled breath condensate of patients with primary ciliary dyskinesia," Chest, vol. 124, no. 2, pp. 633638, 2003.

[188] A. Sandrini, I. M. Ferreira, C. Gutierrez, J. R. Jardim, N. Zamel, and K. R. Chapman, "Effect of montelukast on exhaled nitric oxide and nonvolatile markers of inflammation in mild asthma," Chest, vol. 124, no. 4, pp. 1334-1340, 2003.

[189] P. Montuschi, E. Ragazzoni, S. Valente et al., "Validation of leukotriene $\mathrm{B}_{4}$ measurements in exhaled breath condensate," Inflammation Research, vol. 52, no. 2, pp. 69-73, 2003.

[190] B. Balint, S. A. Kharitonov, T. Hanazawa et al., "Increased nitrotyrosine in exhaled breath condensate in cystic fibrosis," European Respiratory Journal, vol. 17, no. 6, pp. 1201-1207, 2001.

[191] F.-C. Cheah, B. A. Darlow, and C. C. Winterbourn, "Problems associated with collecting breath condensate for the measurement of exhaled hydrogen peroxide from neonates on respiratory support," Biology of the Neonate, vol. 84, no. 4, pp. 338-341, 2003.

[192] A. Bruhn, L. Liberona, C. Lisboa, and G. Borzone, "Limitations of the technique to determine hydrogen peroxide levels in exhaled breath condensate from patients with adult respiratory distress syndrome," Archivos de Bronconeumologia, vol. 41, no. 10, Article ID 77.251, pp. 542-546, 2005.

[193] V. A. Goncharova, L. V. Borisenko, E. K. Dotsenko, and M. A. Pokhaznikova, "Kallikrein-kinin indices and biological composition of exhaled condensate in acute bronchitis patients with varying disease course," Klinicheskaia Meditsina, vol. 74, no. 7, pp. 46-48, 1996.

[194] L. Scheideler, H.-G. Manke, U. Schwulera, O. Inacker, and H. Hammerle, "Detection of nonvolatile macromolecules in breath: a possible diagnostic tool?" American Review of Respiratory Disease, vol. 148, no. 3, pp. 778-784, 1993.

[195] E. Baraldi, L. Ghiro, V. Piovan, S. Carraro, F. Zacchello, and S. Zanconato, "Safety and success of exhaled breath condensate collection in asthma," Archives of Disease in Childhood, vol. 88, no. 4, pp. 358-360, 2003.

[196] American Thoracic Society, “ATS workshop proceedings: exhaled nitric oxide and nitric oxide oxidative metabolism in exhaled breath condensate," Proceedings of the American Thoracic Society, vol. 3, pp. 131-145, 2006.

[197] I. Horváth, J. Hunt, P. J. Barnes et al., "Exhaled breath condensate: methodological recommendations and unresolved questions," European Respiratory Journal, vol. 26, no. 3, pp. 523-548, 2005.

[198] J. Liu and P. S. Thomas, "Relationship between exhaled breath condensate volume and measurements of lung volumes," Respiration, vol. 74, no. 2, pp. 142-145, 2007.

[199] A. S. Jackson, A. Sandrini, C. Campbell, S. Chow, P. S. Thomas, and D. H. Yates, "Comparison of biomarkers in exhaled breath condensate and bronchoalveolar lavage," American Journal of Respiratory and Critical Care Medicine, vol. 175, no. 3, pp. 222227, 2007.

[200] K. Hildebrand, R. Krenke, T. Przybyłowski, A. Fangrat, K. Górska, and R. Chazan, "Influence of bronchoscopy on nitric oxide in exhaled air," Pneumonologia i Alergologia Polska, vol. 74, no. 1, pp. 26-31, 2006.

[201] P. Montuschi, S. Martello, M. Felli, C. Mondino, P. J. Barnes, and M. Chiarotti, "Liquid chromatography/mass spectrometry analysis of exhaled leukotriene B4 in asthmatic children," Respiratory Research, vol. 6, article 119, 2005.

[202] D. Kohlmuller and W. Kochen, "Is n-pentane really an index of lipid peroxidation in humans and animals? A methodological reevaluation," Analytical Biochemistry, vol. 210, no. 2, pp. 268276, 1993.

[203] S. Mendis, P. A. Sobotkaferdin, C. Leja, and D. E. Euler, "Breath pentane and plasma lipid peroxides in ischemic heart disease," Free Radical Biology and Medicine, vol. 19, no. 5, pp. 679-684, 1995.

[204] D. W. Holt, A. Johnston, and J. D. Ramsey, "Breath pentane and heart rejection," Journal of Heart and Lung Transplantation, vol. 13, no. 6, pp. 1147-1148, 1994.

[205] S. Zevin and N. L. Benowitz, "Drug interactions with tobacco smoking. An update," Clinical Pharmacokinetics, vol. 36, no. 6, pp. 425-438, 1999.

[206] M. Pasanen and O. Pelkonen, "The expression and environmental regulation of $\mathrm{P} 450$ enzymes in human placenta," Critical Reviews in Toxicology, vol. 24, no. 3, pp. 211-229, 1994.

[207] D. W. Nebert, D. D. Petersen, and A. Puga, "Human AH locus polymorphism and cancer: inducibility of CYP1A1 and other genes by combustion products and dioxin," Pharmacogenetics, vol. 1, no. 2, pp. 68-78, 1991.

[208] F. Deveci and N. Ilhan, "Plasma malondialdehyde and serum trace element concentrations in patients with active pulmonary tuberculosis," Biological Trace Element Research, vol. 95, no. 1, pp. 29-38, 2003. 
[209] S. Kwiatkowska, G. Piasecka, M. Zieba, W. Piotrowski, and D. Nowak, "Increased serum concentrations of conjugated diens and malondialdehyde in patients with pulmonary tuberculosis," Respiratory Medicine, vol. 93, no. 4, pp. 272-276, 1999.

[210] S. Kwiatkowska, M. Łuczyńska, I. Grzelewska-Rzymowska, D. Nowak, and M. Zięba, "Comparison of oxidative stress markers in exhaled breath condensate and in serum of patients with tuberculosis and sarcoidosis," Polski Merkuriusz Lekarski, vol. 19, no. 109, pp. 37-40, 2005.

[211] E. Bargagli, A. Mazzi, and P. Rottoli, "Markers of inflammation in sarcoidosis: blood, urine, BAL, sputum, and exhaled gas," Clinics in Chest Medicine, vol. 29, no. 3, pp. 445-458, 2008.

[212] E. Ceylan, A. Gülsün, M. Gencer, and N. Aksoy, "A new parameter in the detection of tuberculosis activity: reactive oxygen metabolites," Respiration, vol. 72, no. 2, pp. 156-159, 2005.

[213] A. D. Smith, J. O. Cowan, K. P. Brassett, G. P. Herbison, and D. R. Taylor, "Use of exhaled nitric oxide measurements to guide treatment in chronic asthma," The New England Journal of Medicine, vol. 352, no. 21, pp. 2163-2258, 2005.

[214] P. Montuschi, "Toward a personalized pharmacotherapy of respiratory diseases," Frontiers in Pharmacology, vol. 1, p. 131, 2010.

[215] J. C. De Jongste, "Surrogate markers of airway inflammation: Inflammometry in paediatric respiratory medicine," Paediatric Respiratory Reviews, vol. 1, no. 4, pp. 354-360, 2000.

[216] J. Berg and P. Lindgren, "Economic evaluation of FENO measurement in diagnosis and 1-year management of asthma in Germany," Respiratory Medicine, vol. 102, no. 2, pp. 219-231, 2008.

[217] L. J. Dupont, M. G. Demedts, and G. M. Verleden, "Prospective evaluation of the validity of exhaled nitric oxide for the diagnosis of asthma," Chest, vol. 123, no. 3, pp. 751-756, 2003.

[218] G. M. Cox, J. Mukherjee, G. T. Cole, A. Casadevall, and J. R. Perfect, "Urease as a virulence factor in experimental cryptococcosis," Infection and Immunity, vol. 68, no. 2, pp. 443-448, 2000.

[219] G. Vass, E. Huszár, E. Barát, and I. Horváth, "Exhaled breath condensate and its analysis-a new method in pulmonology," Orvosi hetilap, vol. 144, no. 51, pp. 2517-2524, 2003.

[220] G. L. Piacentini, D. Peroni, E. Crestani et al., "Exhaled air temperature in asthma: methods and relationship with markers of disease," Clinical and Experimental Allergy, vol. 37, no. 3, pp. 415-419, 2007.

[221] K. Czebe, I. Barta, B. Antus, M. Valyon, I. Horváth, and T. Kullmann, "Influence of condensing equipment and temperature on exhaled breath condensate $\mathrm{pH}$, total protein and leukotriene concentrations," Respiratory Medicine, vol. 102, no. 5, pp. 720 725, 2008.

[222] M. Goldoni, A. Caglieri, R. Andreoli et al., "Influence of condensation temperature on selected exhaled breath parameters," BMC Pulmonary Medicine, vol. 5, article 10, 2005.

[223] P. P. Rosias, C. M. Robroeks, H. J. Niemarkt et al., "Breath condenser coatings affect measurement of biomarkers in exhaled breath condensate," European Respiratory Journal, vol. 28, no. 5, pp. 1036-1041, 2006.

[224] L. M. Gonzalez-Reche, A. K. Musiol, A. Müller-Lux, T. Kraus, and T. Göen, "Method optimization and validation for the simultaneous determination of arachidonic acid metabolites in exhaled breath condensate by liquid chromatography-electrospray ionization tandem mass spectrometry," Journal of Occupational Medicine and Toxicology, vol. 1, no. 1, article 5, 2006.
[225] C. R. Esther Jr., H. M. Jasin, L. B. Collins, J. A. Swenberg, and G. Boysen, "A mass spectrometric method to simultaneously measure a biomarker and dilution marker in exhaled breath condensate," Rapid Communications in Mass Spectrometry, vol. 22, no. 5, pp. 701-705, 2008.

[226] T. Tanahashi, T. Kodama, Y. Yamaoka et al., "Analysis of the13Curea breast test for detection of Helicobacter pylori infection based on the kinetics of $\Delta-13 \mathrm{CO}_{2}$ using laser spectroscopy," Journal of Gastroenterology and Hepatology, vol. 13, no. 7, pp. 732-737, 1998.

[227] A. Kaul, D. K. Bhasin, C. M. Pathak et al., "Normal limits of 14C-urea breath test," Tropical Gastroenterology, vol. 19, no. 3, pp. 110-113, 1998.

[228] N. Nelson, V. Lagesson, A. R. Nosratabadi, J. Ludvigsson, and C. Tagesson, "Exhaled isoprene and acetone in newborn infants and in children with diabetes mellitus," Pediatric Research, vol. 44, no. 3, pp. 363-367, 1998.

[229] W. A. Groves and E. T. Zellers, "Prototype instrument employing a microsensor array for the analysis of organic vapors in exhaled breath," American Industrial Hygiene Association Journal, vol. 57, no. 12, pp. 1103-1108, 1996.

[230] P. Španěl and D. Smith, "Selected ion flow tube: a technique for quantitative trace gas analysis of air and breath," Medical and Biological Engineering and Computing, vol. 34, no. 6, pp. 409419, 1996. 


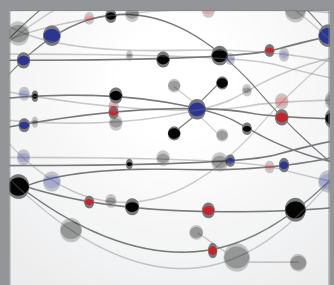

The Scientific World Journal
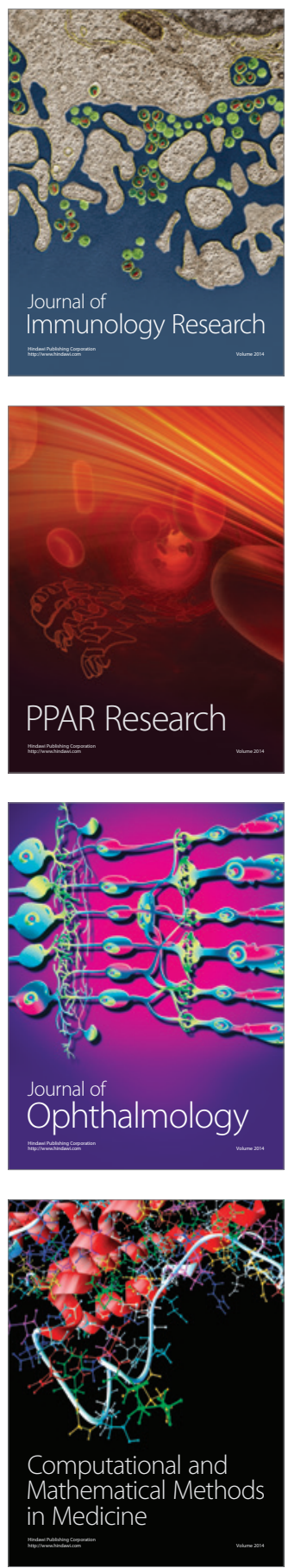

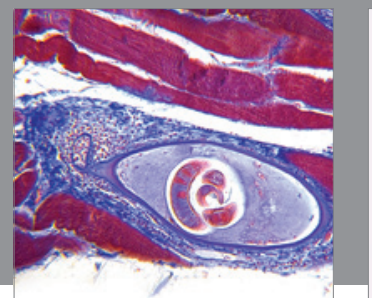

Gastroenterology

Research and Practice
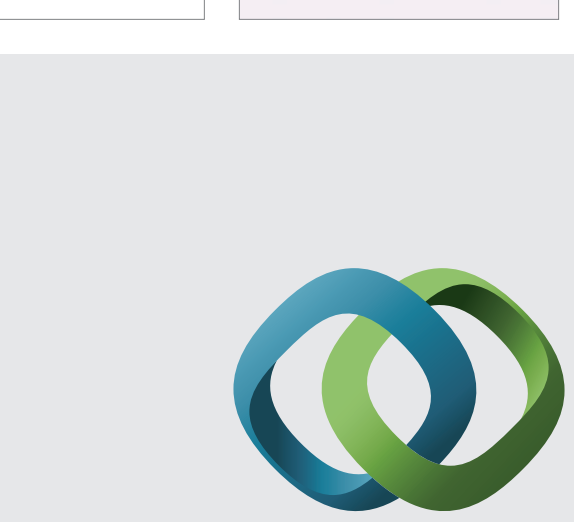

\section{Hindawi}

Submit your manuscripts at

http://www.hindawi.com
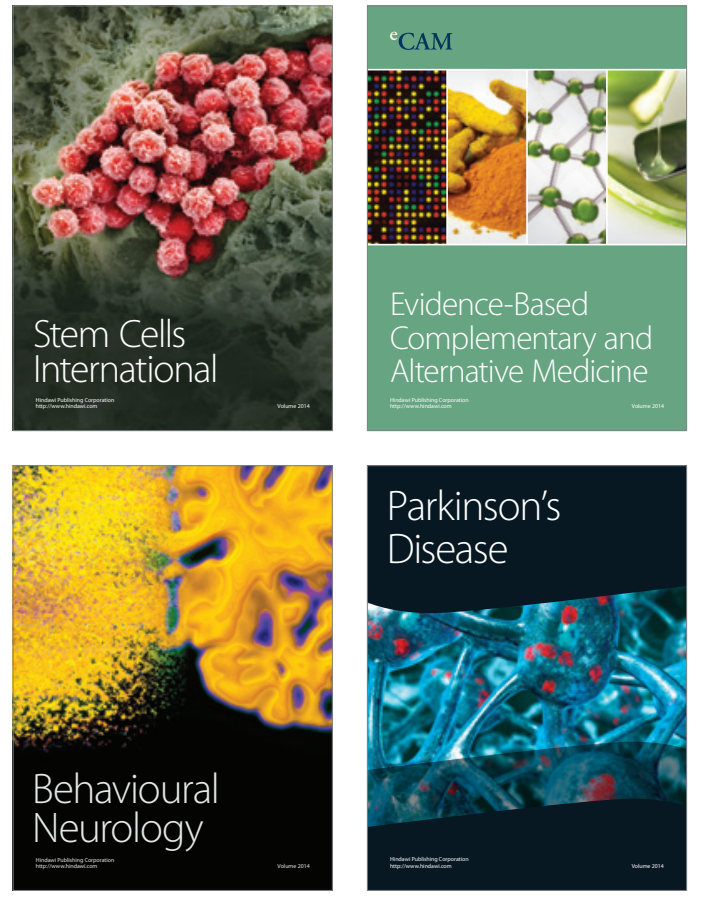
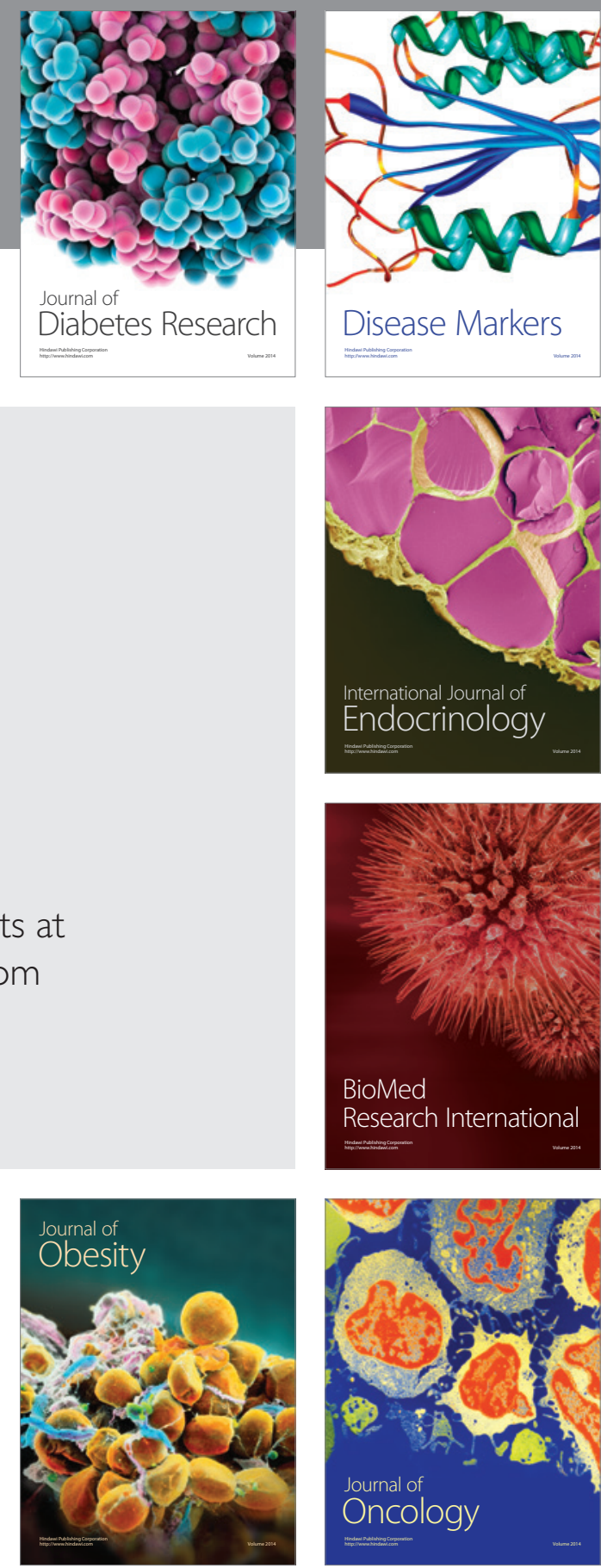

Disease Markers
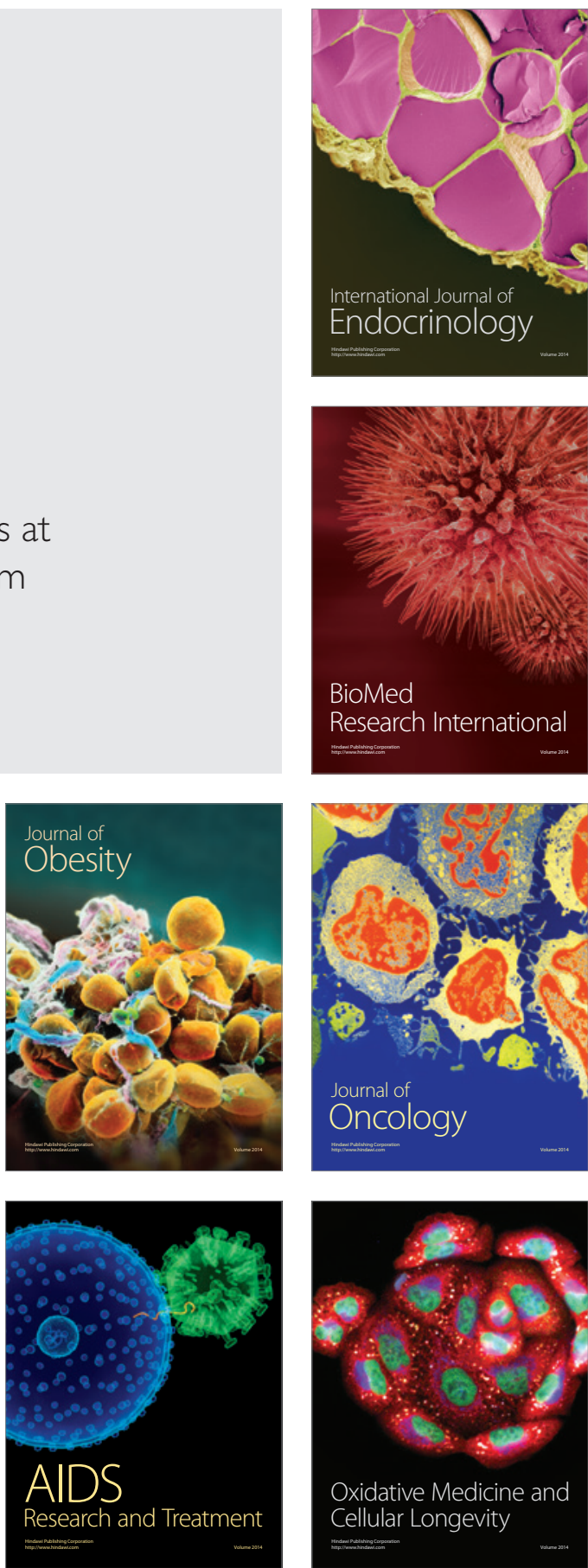